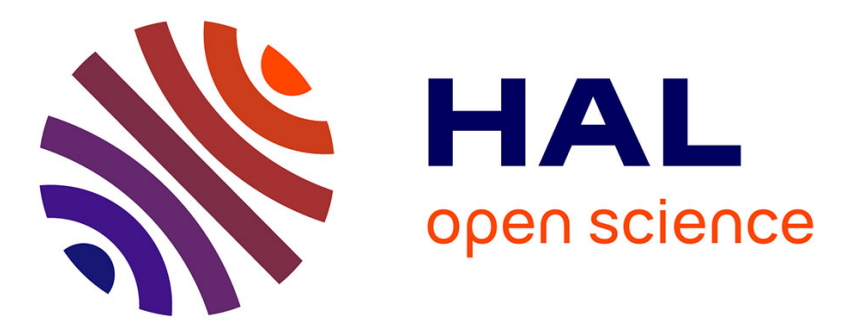

\title{
Stabilizing electrode/electrolyte interface in Li-S batteries using liquid/solid Li2S-P2S5 hybrid electrolyte
} Y.-H. Xu, W.-Z. Li, B. Fan, P. Fan, Z.-K. Luo, F. Wang, Xianghua Zhang, Hongli Ma, B. Xue

\section{- To cite this version:}

Y.-H. Xu, W.-Z. Li, B. Fan, P. Fan, Z.-K. Luo, et al.. Stabilizing electrode/electrolyte interface in Li-S batteries using liquid/solid Li2S-P2S5 hybrid electrolyte. Applied Surface Science, 2021, 546, pp.149034. 10.1016/j.apsusc.2021.149034 . hal-03157972

\section{HAL Id: hal-03157972 \\ https://hal.science/hal-03157972}

Submitted on 8 Mar 2021

HAL is a multi-disciplinary open access archive for the deposit and dissemination of scientific research documents, whether they are published or not. The documents may come from teaching and research institutions in France or abroad, or from public or private research centers.
L'archive ouverte pluridisciplinaire HAL, est destinée au dépôt et à la diffusion de documents scientifiques de niveau recherche, publiés ou non, émanant des établissements d'enseignement et de recherche français ou étrangers, des laboratoires publics ou privés. 


\section{Stabilizing electrode/electrolyte interface in Li-S batteries using liquid/solid $\mathrm{Li}_{2} \mathrm{~S}-\mathrm{P}_{2} \mathrm{~S}_{5}$ hybrid electrolyte}

Yang-Hai Xü ${ }^{\mathrm{a}, \mathrm{b}}$, Wen-Zhi Lic ${ }^{\mathrm{c}}$, Bo Fan ${ }^{\mathrm{a}, \mathrm{f}, *}$, Ping Fan ${ }^{\mathrm{a}}$, Zhong-Kuan Luo ${ }^{\mathrm{d}}$, Fang Wang ${ }^{\mathrm{d}}$, Xiang-Hua Zhang ${ }^{\mathrm{a}, \mathrm{e}}$, Hong-Li Ma ${ }^{\mathrm{e}}$, Bai Xue ${ }^{\mathrm{a}, *}$

${ }^{a}$ Shenzhen Key Laboratory of Advanced Thin Films and Applications, Institute of Thin Film Physics and Applications, College of Physics and Energy, Shenzhen University, 518060 Shenzhen, China.

b Key Laboratory of Optoelectronic Devices and Systems of Ministry of Education and Guangdong Province, College of Optoelectronic Engineering, Shenzhen University, Shenzhen 518060, China.

${ }^{c}$ College of Materials Science and Engineering, Shenzhen University, 3688 Nanhai Avenue, Nanshan District, Shenzhen, 518060, China.

${ }^{d}$ College of Chemistry and Environmental Engineering, Shenzhen University, 3688 Nanhai Avenue, Nanshan District, Shenzhen, 518060, China.

${ }^{\mathrm{e}}$ Laboratory of Glasses and Ceramics, Institute of Chemical Science, University of Rennes 1, Rennes, France.

${ }_{\mathrm{f}}^{\mathrm{S}}$ State Key Lab of Silicon Materials, Zhejiang University, Hangzhou, 310027, China.

*Corresponding author: fanb07@hotmail.com; baixue@szu.edu.cn.

\section{ABSTRACT}

Lithium-sulfur (Li-S) batteries using hybrid electrolytes, which are composed of solid-electrolyte separator and liquid-electrolyte wetting agent, can effectively eliminate the polysulfide shuttling issue. The cycling performance of these hybrid 
batteries is mainly limited by the interfacial stability between the solid and liquid electrolytes. This work detailly discusses the influence of the composition on the stability of a highly ionic conductive sulfide solid electrolyte, lithium thiophosphate $\mathrm{xLi}_{2} \mathrm{~S} \cdot(100-\mathrm{x}) \mathrm{P}_{2} \mathrm{~S}_{5}(70 \leq \mathrm{x} \leq 75, \mathrm{SSEs})$, in hybrid Li-S batteries. It reveals that the solid electrolyte with low $\mathrm{Li}_{2} \mathrm{~S}$ content favors the formation of a SEI layer containing $\mathrm{Li}_{3} \mathrm{PS}_{4}$ and therefore improves the interfacial stability with $\mathrm{Li}$ anode, while the one with high $\mathrm{Li}_{2} \mathrm{~S}$ content behaves more stable with the cathode. Using $75 \mathrm{Li}_{2} \mathrm{~S} \cdot 25 \mathrm{P}_{2} \mathrm{~S}_{5}$ as the separator, a hybrid battery runs more than 400 cycles with a low capacity fading rate of $0.14 \% /$ cycle. This is benefited from the elimination of polysulfide shutting and especially the excellent compatibility of the sulfide solid electrolyte with both anode and cathode.

(a)

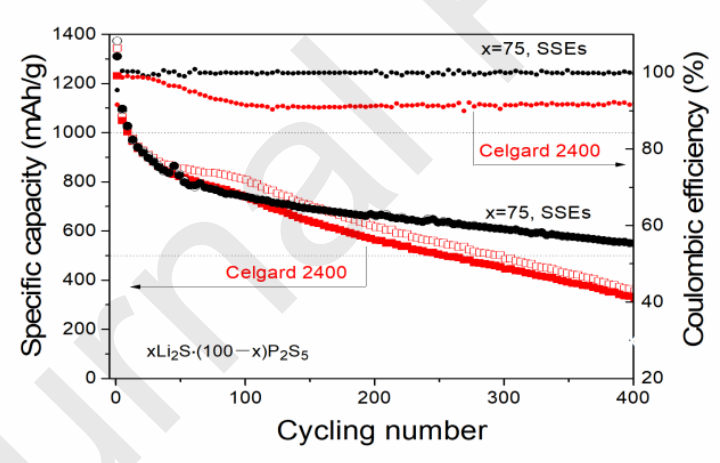

(b)

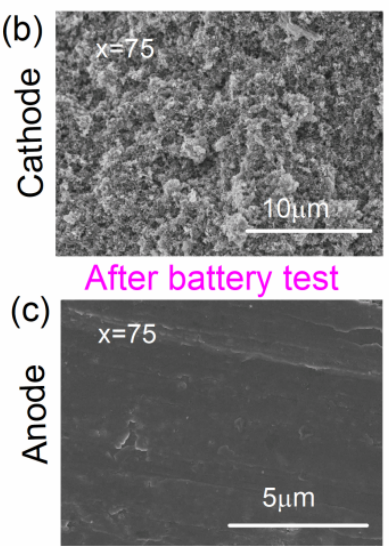

Hybrid Li-S battery $(x=75)$ yields 400 cycles due to its excellent compatibility with the electrodes.

Key words: lithium thiophosphates, $75 \mathrm{Li}_{2} \mathrm{~S}-25 \mathrm{P}_{2} \mathrm{~S}_{5}$, hybrid electrolyte, Li-S battery, interfacial stability.

\section{Introduction}

Lithium-sulfur batteries, possessing a theoretical specific capacity of 1672 $\mathrm{mAh} / \mathrm{g}$ and an average voltage of $2.15 \mathrm{~V}[1,2]$, is promising to construct energy 
storage system for electrical vehicles running more than $400 \mathrm{~km}$ [3]. However, it encounters serious challenges including poor conductivity of sulfur and lithium sulfides, shuttle problems of lithium polysulfides and uncontrolled growth of lithium dendrites, which result in poor rate capability [4], capacity fading [5], coulombic efficiency declining and even cell short-circuit [6]. To cope with polysulfides shuttling, various strategies are focused on modifying cathode structure $[7,8,9]$, tuning electrolyte composition $[10,11,12]$, optimizing the interface $[13,14]$ and controlling the electrochemical process $[15,16]$. However, the shuttle problems cannot be completely eliminated.

Replacing the conventional organic liquid electrolyte with polymer electrolytes [17] or dense inorganic solid electrolytes $[18,19]$, provides an opportunity to eliminate the polysulfides shuttling problem. Simply utilizing polymer electrolytes [20] or solid electrolytes usually leads to unsatisfactory rate performance of the batteries due to the poor ionic conductivity at room temperature and poor contact and instability issues between electrolytes and electrodes [21,22]. As a result, it gives birth of the concept of hybrid Li-S batteries, where inorganic solid electrolyte being used as polysulfide barrier and organic electrolyte [23,24], ionic liquid electrolyte [25,26] or gel-polymers $[27,28]$ used as wetting agent to improve interfacial contact and as high-speed bridge for fast $\mathrm{Li}^{+}$transportation [29,30]. Oxides, such as LAGP $\left(\mathrm{Li}_{1.5} \mathrm{Al}_{0.5} \mathrm{Ge}_{1.5}\left(\mathrm{PO}_{4}\right)_{3}\right)$ [24,31] and LATP $\left(\mathrm{Li}_{1.3} \mathrm{Al}_{0.3} \mathrm{Ti}_{1.7}\left(\mathrm{PO}_{4}\right)_{3}\right)$ [32], etc., are the most used solid electrolytes for inorganic separators. However, their low ionic conductivity and poor contact with cathode cannot satisfy high rate performance. Sulfide solid electrolytes (SSEs), such 
as, $\mathrm{Li}_{10} \mathrm{GeP}_{2} \mathrm{~S}_{12}\left(12 \mathrm{mS} \mathrm{cm}{ }^{-1}\right)$ [33], $\mathrm{Li}_{7} \mathrm{P}_{3} \mathrm{~S}_{11}\left(17 \mathrm{mS} \mathrm{cm}{ }^{-1}\right)$ [34], $\mathrm{Li}_{10} \mathrm{SnP}_{2} \mathrm{~S}_{12}(4 \mathrm{mS}$ $\left.\mathrm{cm}^{-1}\right)$ [35], $\mathrm{Li}_{9.54} \mathrm{Si}_{1.74} \mathrm{P}_{1.44} \mathrm{~S}_{11.7} \mathrm{Cl}_{0.3}\left(25 \mathrm{mS} \mathrm{cm}^{-1}\right)$ [36] and $\mathrm{Li}_{6} \mathrm{PS}_{5} \mathrm{Cl}\left(3.15 \mathrm{mS} \mathrm{cm}^{-1}\right)$ [37], are more attractive than oxides due to their superior ionic conductivity and feasible deformability at ambient temperature.

Despite such advantages, many highly-conductive sulfide electrolytes have an unstable interface against $\mathrm{Li}$ anode [38,39]. For example, the reaction between $\mathrm{Li}_{10} \mathrm{GeP}_{2} \mathrm{~S}_{12}$ and $\mathrm{Li}$ leads to the formation of a continuously growing interphase layer composed of $\mathrm{Li}_{3} \mathrm{P}, \mathrm{Li}_{2} \mathrm{~S}$, and $\mathrm{Li}-\mathrm{Ge}$ alloy, which increases the interfacial resistance [40]. In order to stabilize Li-sulfide electrolytes interface, a solid electrolyte interphase (SEI) is necessarily built up between them [41]. LiF is proposed as one key component in SEI due to its excellent electronic insulating and ionic conducting property, not only allowing sufficiently fast Li-ion kinetics but also more importantly promoting the electrodeposition of $\mathrm{Li}$ in a parallel rather than vertical manner $[42,43]$. In situ modification of the interface between $\mathrm{Li}$ metal and $\mathrm{Li}_{10} \mathrm{SnP}_{2} \mathrm{~S}_{12}$ with specific ionic liquid and salts leads to the enrichment of LiF in the SEI layer [44]. An in situ and self-limiting reaction between $\mathrm{P}_{4} \mathrm{~S}_{16}$ and Li in N-methyl-2-pyrrolidone enables formation of $\mathrm{Li}_{3} \mathrm{PS}_{4}$ solid-state electrolyte protection layer on the surface of $\mathrm{Li}$, which can also address the dynamic plating/stripping process of Li metal [45].

The stability between solid electrolytes and cathodes is also a key factor that determines the performance of hybrid batteries. For example, in hybrid Li-S batteries the NASICON-type solid electrolyte $\mathrm{Li}_{1+\mathrm{x}} \mathrm{Ti}_{2-\mathrm{x}} \mathrm{Al}_{\mathrm{x}}\left(\mathrm{PO}_{4}\right)_{3}$ gets lithiated in contact with lithium polysulfide solution and $\mathrm{Li}_{2} \mathrm{CO}_{3}$ is formed on the particle surface, blocking 
the interfacial lithium-ion transport between the liquid and solid-state electrolytes [32]. In our recent work, the hybrid Li-S batteries, based on $\mathrm{Li}_{10} \mathrm{SnP}_{2} \mathrm{~S}_{12}$ sulfide solid electrolyte, successfully run more than 100 cycles under an extremely high rate of 5C $\left(7.10 \mathrm{~mA} / \mathrm{cm}^{2}\right)$ and maintain good capacity and coulombic efficiency [46]. However, $\mathrm{Li}_{10} \mathrm{SnP}_{2} \mathrm{~S}_{12}$, which contains tetravalent $\mathrm{Sn}^{4+}$, is not so stable with both the cathode and the anode, thus initiating continuously unwanted parasitic reactions.

Here, lithium thiophosphates $\mathrm{xLi}_{2} \mathrm{~S} \cdot(100-\mathrm{x}) \mathrm{P}_{2} \mathrm{~S}_{5} \quad(70 \leq \mathrm{x} \leq 75$, SSEs $)$, which exclude tetravalent metal elements, are used as the solid electrolyte separator for hybrid Li-S batteries. The influence of $\mathrm{Li}_{2} \mathrm{~S}$ content of lithium thiophosphates on their interfacial stability with the $\mathrm{Li}$ anode and the cathode is detailly investigated. After achieving both stable interfaces with the $\mathrm{Li}$ anode and the cathode by adjusting the $\mathrm{Li}_{2} \mathrm{~S}$ content, the lithium thiophosphates $75 \mathrm{Li}_{2} \mathrm{~S} \cdot 25 \mathrm{P}_{2} \mathrm{~S}_{5}$ is used to fabricate a high-performance Li-S battery which successfully runs more than 400 cycles at $0.2 \mathrm{C}$.

\section{Experimental}

\subsection{Materials preparation}

Lithium thiophosphates $\mathrm{xLi}_{2} \mathrm{~S} \cdot(100-\mathrm{x}) \mathrm{P}_{2} \mathrm{~S}_{5} \quad(70 \leq \mathrm{x} \leq 75)$ were prepared by conventional ball-milling method plus low temperature annealing. 4 g mixture of $\mathrm{Li}_{2} \mathrm{~S}$ (99.99\%, Alfa Aesar) and $\mathrm{P}_{2} \mathrm{~S}_{5}$ (Sigma-Aldrich, $\geq 99 \%$ ) was put into a 45-ml tungsten carbide jar with three tungsten carbide grinding balls $(\varphi=10 \mathrm{~mm})$. The content of $\mathrm{Li}_{2} \mathrm{~S}$ (mole ratio) was precisely controlled to $70 \%, 71.25 \%, 72.5 \%, 73.75 \%$ and $75 \%$, respectively. Then ball milling was conducted at $450 \mathrm{rpm}$ in intermittent manner 
(5-min run/ 6-min pause) using a planetary ball mill apparatus (Pulverisette 7, Fritsch $\mathrm{GmbH}$, Germany). The pause aims to prevent the overheat of the samples that may leads to sulfur evaporation. The effective milling time was $70 \mathrm{~h}$. To gain better homogeneity, the agglomerated powder was intermittently ground every 8-h milling. All the operations were carried out in an argon-filled glove-box $\left(\mathrm{O}_{2}<0.5 \mathrm{ppm}, \mathrm{H}_{2} \mathrm{O}<\right.$ $0.5 \mathrm{ppm})$. The resultant $\mathrm{Li}_{2} \mathrm{~S}-\mathrm{P}_{2} \mathrm{~S}_{5}$ glass powder was then cold-pressed into pellets $(\varphi 15 \mathrm{~mm} \times 1.1 \mathrm{~mm})$ under a pressure of $330 \mathrm{MPa}$. The pellets were sealed in silica glass tubes under vacuum $\left(10^{-3} \mathrm{~Pa}\right)$ and sintered at $260^{\circ} \mathrm{C}$ for $1 \mathrm{~h}$. The highly ionic conductive lithium thiophosphate separators (SSEs) were then obtained.

\subsection{Materials characterization method}

X-ray diffraction (D8 Advance, Bruker AXS GmbH, Germany) and Raman spectra (inVia, Renishaw Inc., UK; loaded with a $532 \mathrm{~nm}$ diode-pumped solid-state laser as the excitation source) were used to monitor the phase evolution during the sample preparation. To avoid moisture, they were mounted in the sample holder and sealed by polyimide films in the glove-box prior to XRD and Raman characterization. The chemical stability of as-obtained sulfide electrolytes with liquid electrolyte was checked by soaking experiments. $300 \mathrm{mg}$ powder of lithium thiophosphates $\mathrm{xLi}_{2} \mathrm{~S} \cdot(100-\mathrm{x}) \mathrm{P}_{2} \mathrm{~S}_{5}(70 \leq \mathrm{x} \leq 75)$ was firstly immersed in $5 \mathrm{ml}$ DME-DOL solvent $(50-50, \mathrm{v} \%)$ for $48 \mathrm{~h}$. The mixture was vigorously shaken every $8 \mathrm{~h}$ and finally vacuum dried at $80{ }^{\circ} \mathrm{C}$ for composition analysis by XRD and Raman spectra. The morphology of the samples after battery test was recorded by a field-emission scanning electron microscope (SU8010, Hitachi Inc., Japan), which was equipped 
with an energy dispersive X-ray micro-analyzer for analyzing the composition of the samples. X-ray photoelectron spectroscopy (XPS) of the samples after battery test was measured using Thermo Scientific ESCALAB 250Xi with Al K $\alpha$-radiation. Vacuum transfer box was used to transfer the samples from glove-box to the characterization equipment. Li foils for SEM and XPS analysis were rinsed by dimethoxyethane (DME) three times in glove-box, and dried under vacuum for one night before test. Thermal analysis of the lithium thiophosphates was carried out by using a differential scanning calorimeter (DSC 3, Mettler Toledo Inc., Switzerland) with a scanning rate of $10^{\circ} \mathrm{C} / \mathrm{min}$ under $\mathrm{N}_{2}$ flow.

The ionic conductivity was measured using an $\mathrm{AC}$ impedance method in an argon filled glove-box with a frequency response analyzer (Solartron 1260A, Solartron Analytical Inc., UK). The as-obtained lithium thiophosphate separators were deposited with gold on both two sides before test. The conductivity of the samples was then determined from the impedance spectra data. The electronic conductivities of lithium thiophosphates were measured by using a DC polarization method with a constant DC voltage of $0.1 \mathrm{~V}$ working on the $\mathrm{Au} / \mathrm{SSEs} / \mathrm{Au}$ cells [47] on the CHI660E electrochemical workstation (CHI660E, CH Instruments Ins., Shanghai, China).

\subsection{Electrochemical measurement}

Button type hybrid Li-S batteries (CR2032) were assembled in a argon-filled glove-box $\left(\mathrm{O}_{2}<0.5 \mathrm{ppm}, \mathrm{H}_{2} \mathrm{O}<0.5 \mathrm{ppm}\right)$ with a structure of -)SUS/Li/ liquid electrolyte (LE)/solid electrolyte (SSEs)/liquid electrolyte/S-C/SUS(+. The cathode was obtained by ultrasonic spraying the ethanol suspension of S-C composite, LA133 
binder and conductive acetylene black $(8: 1: 1, \mathrm{wt} \%)$ on carbon paper, where the S-C composite was prepared in advance by heating the ground mixture of ketjen black and $\mathrm{S}$ at $155^{\circ} \mathrm{C}$ for $12 \mathrm{~h}$ under vacuum with $60 \mathrm{wt} \%$ sulfur loading in the composite. The sulfur load in the cathode was $0.85 \mathrm{mg} \mathrm{cm}^{-2}$. The cathode and both sides of the SE separator were wetted by organic liquid electrolyte (10mL (Anode)/ 30mL (Cathode) LE, 1 M LiTFSI DME/DOL (dimethoxyethane/1,3-dioxolane, 50-50 vol\%)-1\% $\mathrm{LiNO}_{3}$ ). The batteries were stored in the glove-box for one night before galvanostatic charge-discharge test on a battery tester (CT2001, Land Ins., Wuhan, China). The cutoff voltage was 1.5 and $2.8 \mathrm{~V}$. The impedance spectra of the batteries were recorded by an electrochemical workstation.

To study the electrochemical stability of different solid electrolyte separators in solid-liquid-hybrid environment, Cyclic voltammetry of -)Li/liquid electrolyte (LE)/solid electrolyte (SSEs)/liquid electrolyte (LE)/SUS(+ asymmetric cells was measured on the CHI660E electrochemical workstation. $10 \mu$ liquid electrolyte (1 M LiTFSI DME/DOL (50-50 vol\%)-1\% $\mathrm{LiNO}_{3}$ ) was dropwise added between the SE separator and the stainless-steel electrode to create the solid-liquid electrolyte interface. Symmetric cells with a structure of Li/liquid electrolyte (LE) /solid electrolyte (SSEs) /liquid electrolyte (LE) /Li were assembled in Swagelok battery moulds. $10 \mu \mathrm{l}$ liquid electrolyte was dropped between the SSEs separator and the Li electrode. Li plating/stripping behaviours of the symmetric cells were measured by the CT2001 battery tester. 


\section{Results and discussion}

\subsection{Materials characterization}

Lithium thiophosphates were synthesized using high energy ball milling plus low temperature annealing. Figure 1a and Figure S1 shows the X-ray diffraction (XRD) spectra of the glass-ceramics and glass samples in the composition range $70 \leq x \leq 75$ for $\mathrm{xLi}_{2} \mathrm{~S} \cdot(100-\mathrm{x}) \mathrm{P}_{2} \mathrm{~S}_{5}$. No diffraction peaks are observed for the glass samples after $70 \mathrm{~h}$ of ball milling, indicating their amorphous state. After annealing at a low temperature of $260{ }^{\circ} \mathrm{C}$ for $1 \mathrm{~h}$, all the glass samples transform into glass-ceramics. The diffraction peaks match well with the $\mathrm{Li}_{7} \mathrm{P}_{3} \mathrm{~S}_{11}$ crystalline at $\mathrm{x}=70$ [48]. As the increase of $\mathrm{Li}_{2} \mathrm{~S}$ content, the major crystalline phase transforms into $\mathrm{Li}_{3} \mathrm{PS}_{4}$ gradually. There exist two phases of $\mathrm{Li}_{7} \mathrm{P}_{3} \mathrm{~S}_{11}$ and $\mathrm{Li}_{3} \mathrm{PS}_{4}$ at $\mathrm{x}=71.25$, which transforms into $\mathrm{Li}_{3} \mathrm{PS}_{4}$ after $\mathrm{x} \geq 72.5$. The glass-ceramic shows integrated diffraction peaks attributed to $\mathrm{Li}_{3} \mathrm{PS}_{4}$ at $\mathrm{x}=75$. It has broad diffraction peaks compared with that of $x=72.5$ and $x=73.75$, which is possibly related with its smaller grain size originating from higher driving force of nucleation during crystallization.

As shown in Figure 1b and Figure S2, the local structure of lithium thiophosphates $x \mathrm{xi}_{2} \mathrm{~S} \cdot(100-\mathrm{x}) \mathrm{P}_{2} \mathrm{~S}_{5}(70 \leq \mathrm{x} \leq 75)$, in both glass-ceramic and glass forms was examined by Raman spectroscopy. The three bands in annealed lithium thiophosphates at $406 \mathrm{~cm}^{-1}, 422 \mathrm{~cm}^{-1}$ and $388 \mathrm{~cm}^{-1}$ can be attributed to $\mathrm{P}_{2} \mathrm{~S}_{7}{ }^{4-}, \mathrm{PS}_{4}{ }^{3-}$ and $\mathrm{P}_{2} \mathrm{~S}_{6}{ }^{4-}$, respectively $[49,50]$. There's a tendency that the signal of $\mathrm{P}_{2} \mathrm{~S}_{7}{ }^{4-}$, which is a principal structural unit of $\mathrm{Li}_{7} \mathrm{P}_{3} \mathrm{~S}_{11}$, weakens as $\mathrm{Li}_{2} \mathrm{~S}$ content increase from $\mathrm{x}=70$ to $\mathrm{x}=75$, while the signal of $\mathrm{PS}_{4}{ }^{3-}$ strengthens synchronously. This is in good agreement 
with the previous $\mathrm{XRD}$ results, which show that the major phase of the glass-ceramic gradually transfers from $\mathrm{Li}_{7} \mathrm{P}_{3} \mathrm{~S}_{11}$ to $\mathrm{Li}_{3} \mathrm{PS}_{4}$ when the $\mathrm{Li}_{2} \mathrm{~S}$ content increases from $70 \%$ to $75 \%$. The signal of $\mathrm{P}_{2} \mathrm{~S}_{6}{ }^{4-}$ is always observed and maintains the same level in the Raman spectroscopy. The signal of $\mathrm{P}_{2} \mathrm{~S}_{6}{ }^{4-}$ unit is less intense in the corresponding as-milled samples than the annealed samples (Figure S2), reflecting the byproducts are mainly generated during the annealing [51].

(a)

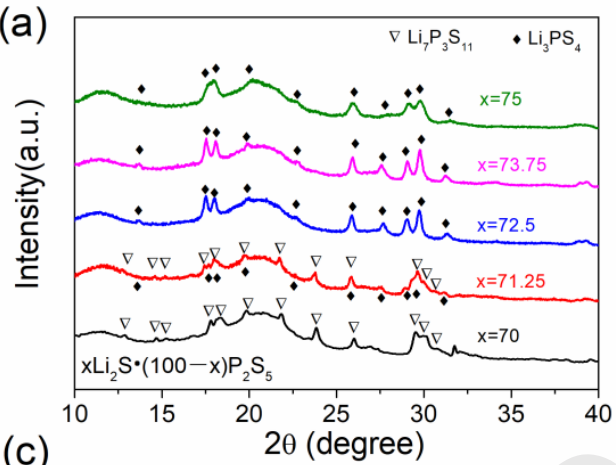

(c)

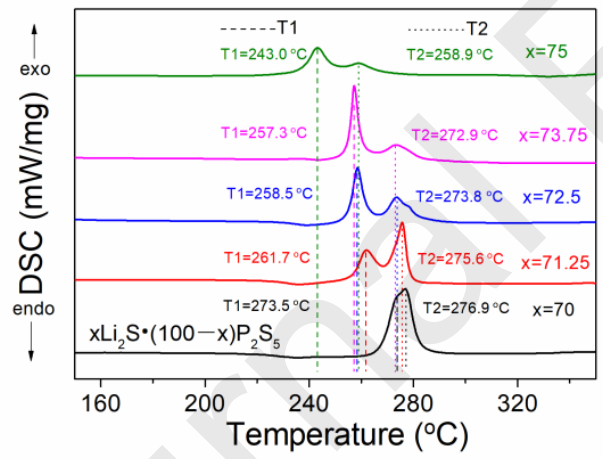

(b)

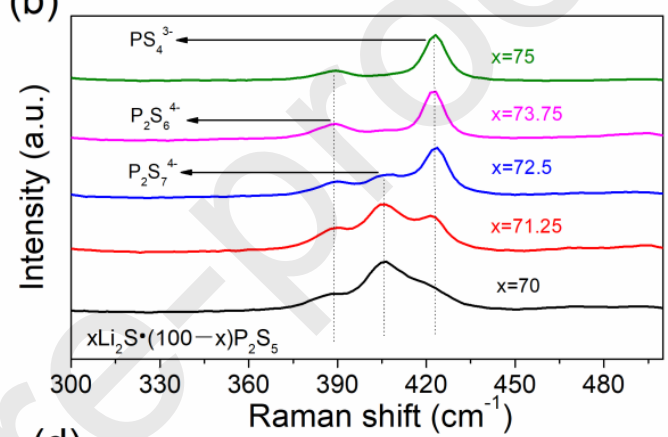

(d)

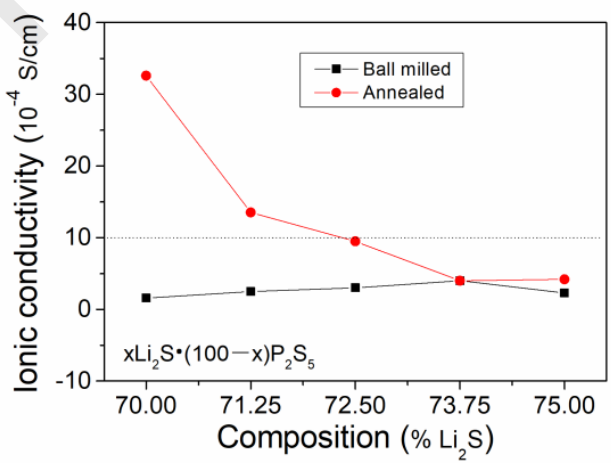

Figure 1. The XRD patterns, Raman spectra, DSC curves and Ionic conductivities of the lithium thiophosphates $\mathrm{xLi}_{2} \mathrm{~S} \cdot(100-\mathrm{x}) \mathrm{P}_{2} \mathrm{~S}_{5}$. (a) XRD profiles of annealed samples; (b) Raman spectra of annealed samples; (c) DSC curves of as-milled samples ; (d) Ionic conductivities of as-milled samples and annealed samples. The two broad XRD bands at about $12^{\circ}$ and $20^{\circ}$ belonging to the kapton tape covering on the samples.

Figure 1c shows the DSC curves of the as-milled amorphous lithium thiophosphates. It's observed that there are two crystallization peaks for all the 
samples, which is in accordance with that reported by Zhang [52]. For the sample $\mathrm{x}=70$, the two crystallization peaks are very close and positioned at $273.5^{\circ} \mathrm{C}(\mathrm{T} 1$, low crystallization temperature) and $276.9^{\circ} \mathrm{C}(\mathrm{T} 2$, high crystallization temperature). With the increase of $\mathrm{Li}_{2} \mathrm{~S}$ content, both of the two crystallization peaks shift to lower temperature (Table 1) and the two crystallization peaks are separated. Meanwhile, the intensities of the T1 peak get strengthened while the intensities of the T2 peak get weakened. The two crystallization peaks at $\mathrm{T} 1$ and $\mathrm{T} 2$ are probably assigned to the formation of $\mathrm{Li}_{3} \mathrm{PS}_{4}$ and $\mathrm{Li}_{7} \mathrm{P}_{3} \mathrm{~S}_{11}$, respectively. The DSC measurement is a dynamic process during which the temperature rises fast $\left(10^{\circ} \mathrm{C} / \mathrm{min}\right)$, and usually shifts the curves to higher temperature than isothermal processes. As shown in Figure 1c, there's obvious onset signal for exothermic process around $260{ }^{\circ} \mathrm{C}$, that is, the crystallization starts. It's feasible to complete the crystallization by extending the annealing time at the onset crystallization temperature. Therefore, the annealing temperature of lithium thiophosphates is chosen to be $260{ }^{\circ} \mathrm{C}$ to get sufficient crystallization [48] and to avoid the undesired decomposition of $\mathrm{Li}_{7} \mathrm{P}_{3} \mathrm{~S}_{11}$ into $\mathrm{Li}_{4} \mathrm{P}_{2} \mathrm{~S}_{6}$ at higher temperature which is detrimental to the conductivity [49]. The annealed sample of $\mathrm{x}=75$ exhibits pure phase of $\mathrm{Li}_{3} \mathrm{PS}_{4}$ similar to $\mathrm{x}=72.5$ and $\mathrm{x}=73.75$ but lower crystallization temperature, which is probably associated with its small grain size and fast nucleation rate mentioned above. This work will not further discuss the influence of the temperature change on the crystallinity, conductivity and structure of SSEs, but just focuses on one temperature of $260^{\circ} \mathrm{C}$.

Table 1. Crystallization temperature (T1, low crystallization temperature; T2, high crystallization 
temperature) for as-milled amorphous lithium thiophosphates $x L i_{2} S \cdot(100-x) P_{2} S_{5}(70 \leq x \leq 75)$ from DSC.

\begin{tabular}{cccccc}
\hline \multirow{2}{*}{ Temperatur } & \multicolumn{5}{c}{ SSEs (Li 2 S content, \%) } \\
\cline { 2 - 6 }$\left({ }^{\circ} \mathrm{C}\right)$ & $\mathrm{x}=70$ & $\mathrm{X}=71.25$ & $\mathrm{X}=72.5$ & $\mathrm{X}=73.75$ & $\mathrm{X}=75$ \\
\hline $\mathrm{T} 1$ & 273.5 & 261.7 & 258.5 & 257.3 & 243.0 \\
$\mathrm{~T} 2$ & 276.9 & 275.6 & 273.8 & 272.9 & 258.9 \\
\hline
\end{tabular}

Figure 1d exhibits the room temperature ionic conductivity of the lithium thiophosphates $x \mathrm{xi}_{2} \mathrm{~S} \cdot(100-\mathrm{x}) \mathrm{P}_{2} \mathrm{~S}_{5}$ after ball milling and subsequent annealing at 260 ${ }^{\circ} \mathrm{C}$ for $1 \mathrm{~h}$. The impedance spectra and DC polarization curves of samples are shown in the Figure S3 and Figure S4, from which the ionic conductivity and electronic conductivity are extracted. It's visualized that all the spectra consist of a high-frequency arc and a low-frequency tail, which can be attributed to the interfacial capacitance and interfacial resistance in parallel, and the polarization near the electrolyte/electrode interface, respectively [53].The ionic conductivity is calculated by equation: $\sigma=L /(A R)$, where $L$ and $A$ are the thickness and area of the samples, and $R$ is resistance determinate by the arc intercept at low frequency. The DC polarization method as described in Ref [47] is used to estimate the electronic conductivity. The information about the ionic conductivity and electronic conductivity of SSEs are summarized in Table S1.

The ionic conductivity of the as-milled lithium thiophosphates firstly increases from $0.16 \mathrm{mS} / \mathrm{cm}$ at $\mathrm{x}=70$ to $0.40 \mathrm{mS} / \mathrm{cm}$ at $\mathrm{x}=73.75$ and then decreases a little. The 
corresponding annealed samples show a contrary trend, where the ionic conductivity exhibits the maximum of $3.3 \mathrm{mS} / \mathrm{cm}$ at $\mathrm{x}=70$ and then gradually decreases to about $0.40 \mathrm{mS} / \mathrm{cm}$. The superior ionic conductivity of the annealed sample at $\mathrm{x}=70$ is related with the formation of highly ionic conductive phase $\mathrm{Li}_{7} \mathrm{P}_{3} \mathrm{~S}_{11}$, and its decrease with the increase of $\mathrm{Li}_{2} \mathrm{~S}$ content is due to the transition of the crystalline phase from $\mathrm{Li}_{7} \mathrm{P}_{3} \mathrm{~S}_{11}$ to $\mathrm{Li}_{3} \mathrm{PS}_{4}$ phase as previously demonstrated by both XRD and Raman spectra. The electronic conductivities of all the SSEs are in the level of $10^{-8} \mathrm{~S} / \mathrm{cm}$, which is about one order of magnitude higher than that of $\mathrm{Li}_{3} \mathrm{PS}_{4}\left(2.2 \times 10^{-9} \mathrm{~S} / \mathrm{cm}\right)$ reported by C. Wang. [47] Such a high electronic conductivity enabling the formation of lithium dendrites is normally detrimental for solid-state Li-metal batteries, especially when the solid electrolyte directly contacts with lithium anode. This drawback is expected to be compensated by introducing a small amount of organic liquid electrolyte between the solid electrolyte and the lithium anode, which will be demonstrated as below in our hybrid Li-S batteries with the lithium thiophosphate separators

\subsection{Battery performance}

Button type Li-S batteries with hybrid electrolyte comprised of lithium thiophosphate separator and normal organic liquid electrolyte (1 M LiTFSI DME/DOL (50-50 vol\%)-1\% $\left.\mathrm{LiNO}_{3}\right)$ were assembled in a glove-box. The electrochemical performance of the hybrid Li-S batteries is shown in the Figure 2 and

Figure S5. The capacity of the batteries decreases during cycling for all the cases $(70 \leq x \leq 75)$, and a majority of the capacity gets lost during the first few cycles. 
Batteries for $70 \leq \mathrm{x} \leq 75$ deliver an initial discharge specific capacity of $1517.1 \mathrm{mAh} / \mathrm{g}$, 1744.1 $\mathrm{mAh} / \mathrm{g}, 1256.5 \mathrm{mAh} / \mathrm{g}, 1406.5 \mathrm{mAh} / \mathrm{g}$ and $1120.2 \mathrm{mAh} / \mathrm{g}$, which decreases to $1083.3 \mathrm{mAh} / \mathrm{g}, 1362.8 \mathrm{mAh} / \mathrm{g}, 895.4 \mathrm{mAh} / \mathrm{g}, 919.8 \mathrm{mAh} / \mathrm{g}$ and $887.6 \mathrm{mAh} / \mathrm{g}$ after experiencing $40^{\text {th }}$ cycling at $0.2 \mathrm{C}$. The corresponding capacity retention stays at $71.40 \%, 78.14 \%, 71.26 \%, 65.40$ and $79.24 \%$, respectively. The exceeding theoretical discharge capacity for $\mathrm{x}=71.25$ is ascribed to the decomposition of sulfides separator when in contact with liquid electrolyte, which participates in electrochemical reaction and contributes extra capacity therefore showing a third charge/discharge plateau. This will be detailly discussed in following Part 3.4.

The electrochemical reactions occurring in the hybrid Li-S batteries are similar to those in conventional liquid Li-S batteries, since the cathodes in both cases are wetted by liquid electrolyte. There are two distinct discharge plateaus located at 2.30 $\mathrm{V}$ and $2.10 \mathrm{~V}$ and two overlapped charge plateaus positioned at $2.32 \mathrm{~V}$, which represent the conversion between $\mathrm{S}_{8}$ and $\mathrm{Li}_{2} \mathrm{~S} / \mathrm{Li}_{2} \mathrm{~S}_{2}$ via the formation of the intermediate lithium polysulfides [1,3]. The initial discharge voltage plateau for $\mathrm{x}=70$ and $\mathrm{x}=71.25$ is slightly higher and their charge potential is slightly lower due to their higher ionic conductivity above $1 \mathrm{mS} / \mathrm{cm}$. However, a pit eventually occurs in the discharge curve for $\mathrm{x}=70$ and $\mathrm{x}=71.25$, and deepens along with the cycling, reflecting serious irreversible polarization occurs. This polarization is associated with the poor electrochemical stability of the two compositions under oxidation condition, which will be discussed later. Finally, the two batteries stop working once the pit voltage reaches the cut-off voltage of $1.50 \mathrm{~V}$. Promisingly, the pit on discharge curves is 
absent for $\mathrm{x}=72.5, \mathrm{x}=73.75$ and $\mathrm{x}=75$, which is supposed to be relevant with the transition of the separator constituent from $\mathrm{Li}_{7} \mathrm{P}_{3} \mathrm{~S}_{11}$ to $\mathrm{Li}_{3} \mathrm{PS}_{4}$. As shown by Figure 2d, the hybrid Li-S batteries of $\mathrm{x}=73.75$ and $\mathrm{x}=75$ show stable second discharge voltage which maintains well during the 50 cycles. The one with $x=73.75$ exhibits the most stable discharge voltage while the one with $\mathrm{x}=75$ exhibits a discharge voltage compromising between good stability and high value.

Coulombic efficiency of all the hybrid Li-S batteries keeps at about $100 \%$ over the whole cycles (Figure 2f). It is therefore confirmed that regardless of their stability issues, all the lithium thiophosphate separators with the studied compositions can effectively block the diffusion of polysulfide ions from cathode to anode. The polysulfide shuttling is no longer a main cause of performance degradation in these hybrid batteries. The distinct difference of the battery performance is principally originated from the different chemical/electrochemical stability of the lithium thiophosphate separators with different $\mathrm{Li}_{2} \mathrm{~S}$ content, which will be discussed in the following three sections.
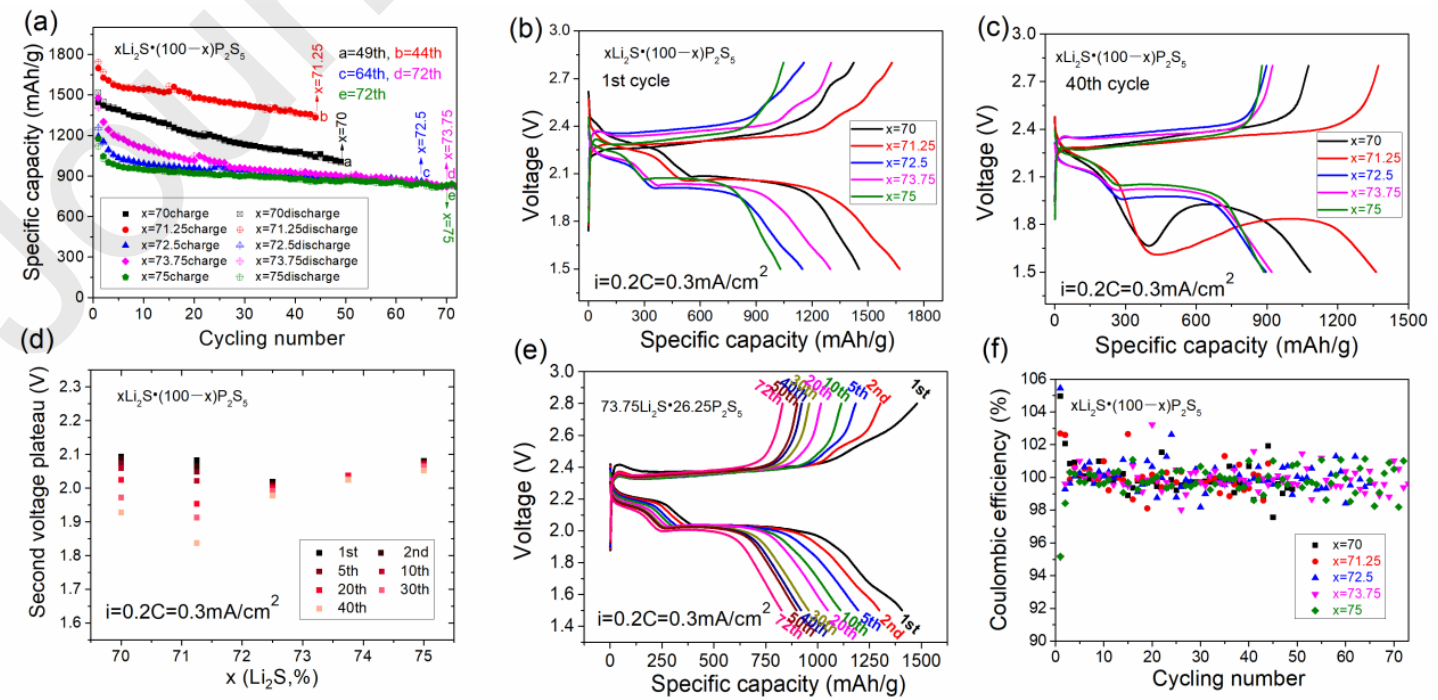

Figure 2. Galvanostatic charge-discharge profiles of the hybrid Li-S batteries at 0.2 C. (a) The 
cycling performance of the hybrid Li-S batteries composed of LE and lithium thiophosphates $\mathrm{xLi}_{2} \mathrm{~S} \cdot(100-\mathrm{x}) \mathrm{P}_{2} \mathrm{~S}_{5}(70 \leq \mathrm{x} \leq 75)$. (b, c) Galvanostatic charge-discharge curves of hybrid Li-S batteries during the first cycling and the $40^{\text {th }}$ cycling $(70 \leq x \leq 75)$. (d) The second discharge voltage plateau for hybrid Li-S batteries $(70 \leq x \leq 75)$ at different cycling. (e) Galvanostatic charge-discharge curves of hybrid Li-S batteries for $x=73.75$. (f) Coulombic efficiency of hybrid Li-S batteries at different cycling $(70 \leq x \leq 75)$.

\subsection{Chemical stability with Ether-Based Solvent}

To evaluate the influence of the composition of the lithium thiophosphates on the electrochemical performance of the hybrid Li-S batteries, the chemical stability of the as-obtained sulfide electrolytes with liquid electrolyte is nonnegligible and should be checked first. The soaking experiment was carried out by immersing $300 \mathrm{mg}$ of lithium thiophosphates $\mathrm{xLi}_{2} \mathrm{~S} \cdot(100-\mathrm{x}) \mathrm{P}_{2} \mathrm{~S}_{5}(70 \leq \mathrm{x} \leq 75)$ into $5 \mathrm{ml}$ DME-DOL solvent $(50-50, \mathrm{v} \%)$ for $48 \mathrm{~h}$. The mixture was vigorously shaken every $8 \mathrm{~h}$ and finally vacuum dried at $80{ }^{\circ} \mathrm{C}$ for composition analysis by XRD and Raman spectra. As shown by the XRD patterns in the Raman spectra (Figure 3b), all the five soaked SSEs display almost identical diffraction peaks which can be attributed to a crystalline phase DME-solvated $\mathrm{Li}_{3} \mathrm{PS}_{4}[54,55]$. There appear two distinctive peaks positioned at $421 \mathrm{~cm}^{-1}$ and $388 \mathrm{~cm}^{-1}$ in Figure $\mathbf{3 b}$, corresponding to ether-solvated $\mathrm{PS}_{4}{ }^{3-}$ anion and ether-solvated vertex-shared $\mathrm{PS}_{4}$ tetrahedral anions [54], respectively. Similar Raman signals have been identified in recent studies on liquid-phase synthesis of $\mathrm{Li}_{7} \mathrm{P}_{3} \mathrm{~S}_{11}$ in acetonitrile $(\mathrm{ACN})$, where the high wavenumber signal is attributed to a crystalline phase $\mathrm{Li}_{3} \mathrm{PS}_{4} \cdot \mathrm{ACN}[56]$ and the low wavenumber signal is attributed to an amorphous 
phase " $\mathrm{Li}_{2} \mathrm{~S} \cdot \mathrm{P}_{2} \mathrm{~S}_{5}$ " $[53,57]$. Therefore, it is supposed that the lithium thiophosphates are decomposed into these two phases by the solvent in our case. It is worth noting that the intensity of the signal at $388 \mathrm{~cm}^{-1}$ decreases with the increasing $\mathrm{Li}_{2} \mathrm{~S}$ content, indicating that less " $\mathrm{Li}_{2} \mathrm{~S} \cdot \mathrm{P}_{2} \mathrm{~S}_{5}$ " releases, especially for the SSEs $\mathrm{x}=73.75$ and $\mathrm{x}=75$.
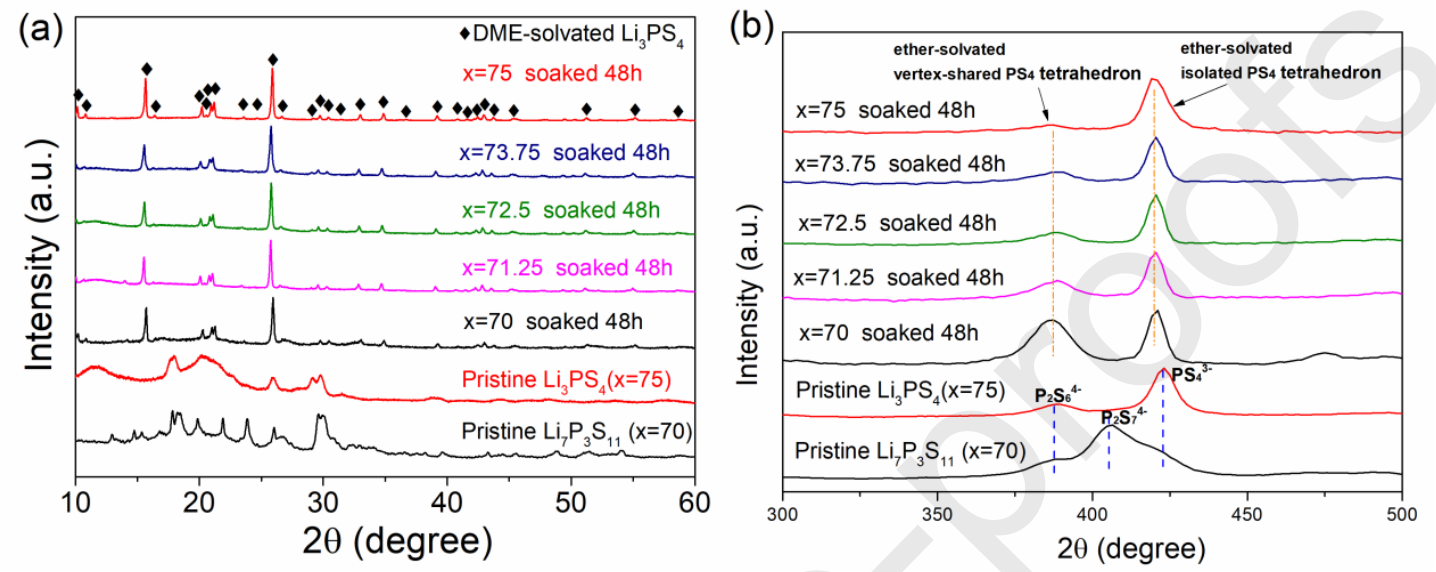

Figure 3. Chemical stability of $\mathrm{Li}_{2} \mathrm{~S}_{-} \mathrm{P}_{2} \mathrm{~S}_{5}$-based glass-ceramic SEs with ether-based solvent. (a)

XRD patterns and (b) Raman spectra of lithium thiophosphates $x \mathrm{Li}_{2} \mathrm{~S} \cdot(100-\mathrm{x}) \mathrm{P}_{2} \mathrm{~S}_{5}(70 \leq \mathrm{x} \leq 75)$ powders after $48 \mathrm{~h}$ soaking in DOL/DME (50-50 vol \%) solvent and before soaking for $\mathrm{Li}_{7} \mathrm{P}_{3} \mathrm{~S}_{11}$ $(\mathrm{x}=70)$ and $\beta-\mathrm{Li}_{3} \mathrm{PS}_{4}(\mathrm{x}=75)$.

\subsection{Electrochemical stability with Li anode}

A stable interface between electrolyte and lithium anode is essential for a lithium metal battery. Li plating/stripping behaviors of Li-LE-SSEs-LE-Li symmetric cells, as shown in Figure 4a, are characterized to explore the interfacial stability of the lithium thiophosphate separators under reduction condition. All the Li symmetric cells, excluding the case of $x=71.25$ and $x=72.5$, display a steady voltage below $0.08 \mathrm{~V}$ and capacity of $0.99 \mathrm{mAh}$ under $0.23 \mathrm{~mA} \mathrm{~cm} \mathrm{~cm}^{-2}$ for a long term of more than $200 \mathrm{~h}$, revealing an excellently stable interface between lithium thiophosphate separators and 
lithium anode with the existence of liquid electrolyte. The Li electrodeposition of 0.99 $\mathrm{mAh}$ at a current density of $0.23 \mathrm{~mA} \mathrm{~cm}^{-2}$ is competitive in solid-state Li symmetric cells [58]. It's puzzled for the short life span of $x=71.25$ and $x=72.5$. Repeated tests of the $\mathrm{Li} / \mathrm{SSEs} / \mathrm{Li}$ symmetric cells were conducted, however short circuit still occurred unavoidably and randomly even for the SSEs $\mathrm{x}=73.75$ with the best cycling performance ( 840 h vs 315 h, see Figure S6). Cracks accidentally formed during cold pressing and sintering of the separators can cause lithium penetration and short circuit of the batteries [59]. The pores and the flaws cannot be avoided in the SSEs pellets which are simply prepared by cold pressing. Furthermore, dendrites can also form at the grain boundaries or even in amorphous sulfide electrolytes free of grain boundaries [60]. The discussion of lithium penetration is beyond the scope of this article. However, from the perspective of stability, these two samples both exhibit stable voltages before short-circuited, indicating their good interfacial stability with lithium anode like other compositions.

The electrochemical impedance spectroscopy (EIS) of the Li symmetric cells is tested and recorded in Figure 4b-c. Two arcs are observed in the EIS for all the Li symmetric cells before and after $30 \mathrm{~h} \mathrm{Li} \mathrm{plating/stripping} \mathrm{test.} \mathrm{The} \mathrm{first} \mathrm{arc} \mathrm{at} \mathrm{high}$ frequency could be attributed to the interfacial resistance, which is impressively decreased after $30 \mathrm{~h}$ continuously plating/striping. The Li symmetric cells for lower $\mathrm{Li}_{2} \mathrm{~S}$ content including $\mathrm{x}=70, \mathrm{x}=71.25$ and $\mathrm{x}=72.5$ exhibit small bulk resistance (matches well with Figure 1d) but large interfacial resistance and charge transfer resistance. Generally, the total resistance of the three samples is small, which 
corresponds to the low overpotential of the Li symmetric cells that is below $0.05 \mathrm{~V}$.

On the contrary, Li symmetric cells of $x=73.75$ and $x=75$ show large bulk resistance but small interfacial resistance and charge transfer resistance, therefore leading to relatively high overpotential of the symmetric cells. The larger interfacial resistance for cells containing lower $\mathrm{Li}_{2} \mathrm{~S}$ content is believed to be related with the formation of thick SEI layer, which will be further demonstrated by SEM and XPS later.

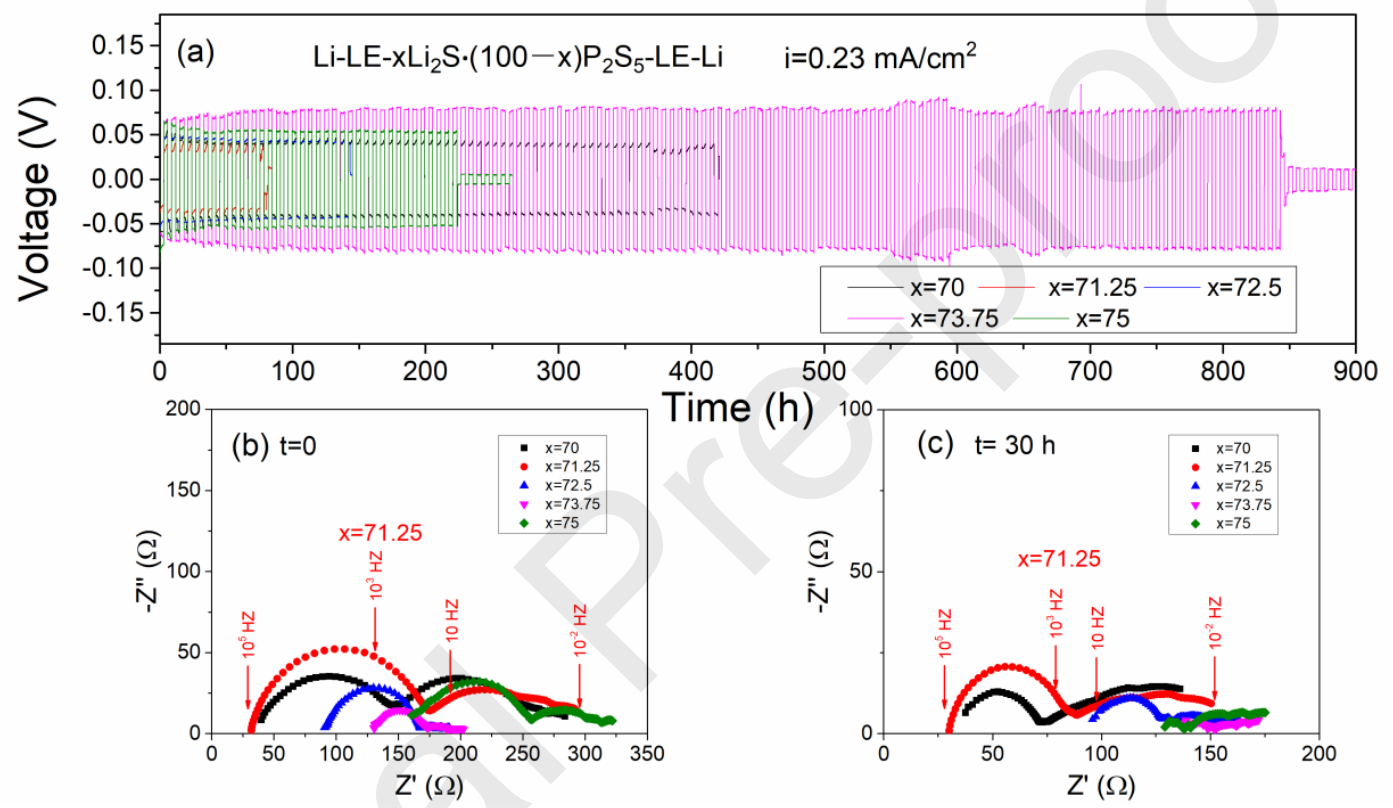

Figure 4. Stability of sulfide solid electrolyte (SSEs)/liquid electrolyte (LE) interface with the lithium electrode and the corresponding electrochemical impedance spectroscopy. The Li plating/stripping profiles is conducted via a symmetric cell structure of Li-LE-SSEs-LE-Li under the current of $0.23 \mathrm{~mA} / \mathrm{cm}^{2}$ for $3 \mathrm{~h}$ during each period of plating or stripping.

Figure 5 displays the morphology (Figure 5a-f) and composition changes (Figure 5g-n) of Li metal surface after the batteries experience 40th charging. It's obvious that the original Li metal shows a plain surface, which becomes coarse after battery cycling due to the formation of a SEI layer. Plenty of unidentified crystals accumulated on Li can be observed for $x=70,71.25$ and 72.5. Some part of the Li 
surface is also covered by a dense thick layer due to orderly stacked crystals (Figure S7). The SEI layer is much thinner for $\mathrm{x}=73.75$ and 75 and therefore they exhibit a relatively smooth surface. The thick SEI layer appearing in the samples with low $\mathrm{Li}_{2} \mathrm{~S}$ content may trigger larger interfacial resistance and charge resistance, which has been revealed by the previous EIS results.
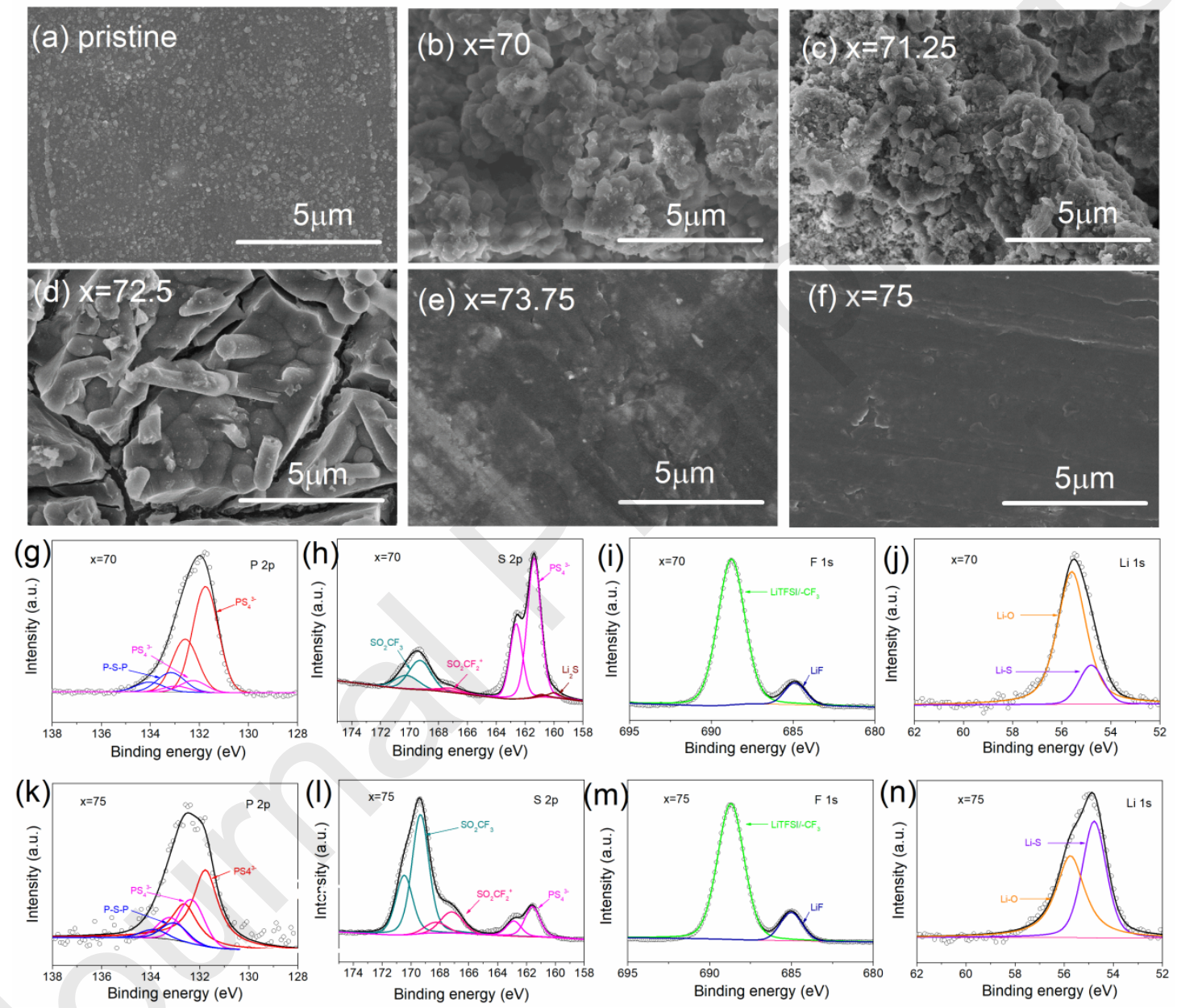

Figure 5. SEM images and XPS spectra of the Li metal surface after battery test. (a-f)

Morphology changes of the Li metal surface before and after battery test for SSEs at $\mathrm{x}=70,71.25$,

72.5, 73.75 and 75. (g-n) XPS analysis for the above Li metal surface of $b(x=70)$ and $f(x=75)$.

X-ray photoelectron spectroscopy (XPS) was further employed to analyze the surface chemistry of the lithium anode after battery cycling. Figure $\mathbf{5} \mathbf{g}-\mathbf{n}$ shows the 
P 2p, S 2p, F 1s and Li 1s XPS spectra for the two typical batteries of $x=70$ and $x=75$.

The P $2 p$ spectrum exhibits several peaks, which can be fitted with three distinct doublets $(2 \mathrm{p} 1 / 2$ and 2p3/2) (Figure 5g, 5k). Among them, the P 2p3/2 peaks appear at $131.7 \mathrm{eV}$ and $132.3 \mathrm{eV}$ can be assigned to $\mathrm{PS}_{4}{ }^{3-}[45,61]$. This assignment is further confirmed by the $S 2 p$ spectrum with one intensive responsive peak of $S 2 p 3 / 2$ at $161.6 \mathrm{eV}$ attributed to $\mathrm{PS}_{4}{ }^{3-}$ (Figure 5h, 5l) $[45,61,62]$. Assigning two different binding energies to $\mathrm{PS}_{4}{ }^{3-}$ reflects that this anion locates in environment with different crystallinity or structural disorder, since amorphization often shifts binding energies in XPS spectra [63]. The strong signal of $\mathrm{PS}_{4}{ }^{3-}$ reveals the existence of $\mathrm{Li}_{3} \mathrm{PS}_{4}$ in the SEI layer on $\mathrm{Li}$ anode. The $\mathrm{P} 2 \mathrm{p} 3 / 2$ peak positioned at $133.2 \mathrm{eV}$ is very weak which is probably related with P-S-P bridging sulfur structure and reflects its low content on Li anode [61]. The $\mathrm{S} 2 \mathrm{p} 3 / 2$ signal also denotes the existence of $-\mathrm{S}^{*} \mathrm{O}_{2} \mathrm{CF}_{3}$ at $169.3 \mathrm{eV}$ and $-\mathrm{S}^{*} \mathrm{O}_{2} \mathrm{CF}_{2}{ }^{+}$at $167.2 \mathrm{eV}$ from the decomposition products of LiTFSI [64], and a trace of $\mathrm{Li}_{2} \mathrm{~S}$ at $160.0 \mathrm{eV}$ [65]. F 1s Signals located at $684.9 \mathrm{eV}$ and $685.2 \mathrm{eV}$ belonging to LiF are also detected (Figure 5i and Figure 5m), which are probably related to the decomposition product of LiTFSI salt with Li metal $[64,66]$. A LiF-rich SEI (above 9\%, Figure S7, Table 2) is helpful to suppress the penetration of $\mathrm{Li}$ dendrites into SSEs, while the low electronic conductivity and the intrinsic electrochemical stability of $\mathrm{LiF}$ block side reactions between the SSEs and $\mathrm{Li}$ [42, 66].Two Li 1s peaks appeared at $54.8 \mathrm{eV}$ and $55.7 \mathrm{eV}$ (Figure 5j, 5n) can be assigned to Li-S bonding $[45,67]$ and Li-O bonding, respectively [68].

As shown in Table 2, the component of S 2s peak attributed to $\mathrm{PS}_{4}{ }^{3-}$ decreases 
from $68.84 \%(x=70)$ to $15 \%(x=75)$, indicating that the lithium thiophosphate with low $\mathrm{Li}_{2} \mathrm{~S}$ content favors the formation of $\mathrm{Li}_{3} \mathrm{PS}_{4}$ in the SEI layer. Our recent study and above chemical stability analysis together reveal that $\mathrm{Li}_{7} \mathrm{P}_{3} \mathrm{~S}_{11}$ tends to be decomposed by ether solvent into solvated $\mathrm{Li}_{3} \mathrm{PS}_{4}$ and " $\mathrm{Li}_{2} \mathrm{~S} \cdot \mathrm{P}_{2} \mathrm{~S}_{5}$ " [57]. It is noteworthy that solvated $\mathrm{Li}_{3} \mathrm{PS}_{4}$ is just solvated rather than dissolved. " $\mathrm{Li}_{2} \mathrm{~S} \cdot \mathrm{P}_{2} \mathrm{~S}_{5}$ " is partially dissolved in the liquid electrolyte, which can diffuse to the Li surface and react with it to form $\mathrm{Li}_{3} \mathrm{PS}_{4}$. This process is similar to the reported studies on in-situ formed $\mathrm{Li}_{3} \mathrm{PS}_{4}$ SEI layers, where phosphor-containing additive is deliberately introduced into the liquid electrolyte to react with $\mathrm{Li}$ to form the $\mathrm{Li}_{3} \mathrm{PS}_{4}$ SEI layers $[69,70]$. Since the lithium thiophosphate with low $\mathrm{Li}_{2} \mathrm{~S}$ content contain more $\mathrm{Li}_{7} \mathrm{P}_{3} \mathrm{~S}_{11}$ or its characteristic structural unit $\mathrm{P}_{2} \mathrm{~S}_{7}{ }^{4-}$, a thick SEI layer rich of $\mathrm{Li}_{3} \mathrm{PS}_{4}$ tends to be formed on the surface of Li anode, as shown by the SEM images in Figure 5b-d. This SEI layer composed of $\mathrm{Li}_{3} \mathrm{PS}_{4}$ and $\mathrm{LiF}$, as demonstrated in the literatures $[45,66]$, can synergistically stabilize the Li metal so that long-term Li plating/stripping cycles is achieved in the Li-LE-SSEs-LE-Li symmetric cells. In summary, lithium thiophosphates with low $\mathrm{Li}_{2} \mathrm{~S}$ content favor the formation of an SEI layer rich of $\mathrm{Li}_{3} \mathrm{PS}_{4}$, so exhibit better electrochemical stability with lithium anode.

Table 2. A detailed information of $\mathrm{PS}_{4}{ }^{3-}$ and $\mathrm{LiF}$ content based on fitting peak area from XPS of the Li metal surface after battery test.

\begin{tabular}{|c|c|c|c|c|c|}
\hline SEI layer & \multicolumn{5}{|c|}{ Component content (Area \%) } \\
\hline Component & $x=70$ & $x=71.25$ & $x=72.5$ & $x=73.75$ & $x=75$ \\
\hline
\end{tabular}




\begin{tabular}{llllll}
$\mathrm{PS}_{4}{ }^{3-}$ & 68.94 & 88.06 & 75.93 & 36.33 & 15.57 \\
$\mathrm{LiF}$ & 9.65 & 14.75 & 67.60 & 41.98 & 14.57 \\
\hline
\end{tabular}

Note: The data is calculated by $\mathrm{PS}_{4}^{3-} / \mathrm{S}_{\text {total area }}$ (based on $\mathrm{S} 2 \mathrm{p} 3 / 2$ ) and $\mathrm{LiF} / \mathrm{F}_{\text {total area }}$ (based on F 1s), respectively.

\subsection{Electrochemical stability with cathode}

The interfacial stability between SSEs and cathode attracts less attention of the electrochemical community than that with lithium anode, but has been unambiguously clarified to be essential for the cycling performance of sulfide-liquid electrolyte-based hybrid Li-S batteries by our previous study [46]. This section will focus on the electrochemistry stability of the lithium thiophosphates with the cathode wetted by ether-based liquid electrolyte. This is firstly characterized by utilizing cyclic voltammetry (CV) method in an asymmetric cell with structure of -) Li/LE-SSEs/LE/SS (stainless-steel)(+ within a potential range of $0.3-3.5 \mathrm{~V}$, which covers the operating voltage of the Li-S battery cathode. As shown in Figure 6a, the $\mathrm{CV}$ curves show an onset oxidation current at about $2.5 \mathrm{~V}$ which dramatically increases to $67 \mu \mathrm{A}$ at $3.5 \mathrm{~V}$ for $\mathrm{x}=70$. During the subsequent cathodic sweep, an onset reduction current occurs at about $2.3 \mathrm{~V}$ and transforms into sharp reduction current peak at $1.5 \mathrm{~V}$. There's similar redox potential for the SSEs of $\mathrm{x}=71.25$ and $\mathrm{x}=72.5$ however with relatively lower anodic and cathodic current. The anodic/ cathodic current is normally accountable for delithiathon/ lithiation of lithium thiophosphate $[71,72]$. For the cases of $x=73.75$ and $x=75$ (corresponding to $\mathrm{Li}_{3} \mathrm{PS}_{4}$ ), two pairs of 
anodic/cathodic current peaks are observed and located at $2.7 \mathrm{~V} / 2.1 \mathrm{~V}$ and $1.0 \mathrm{~V} / 0.7$ $\mathrm{V}$, respectively, all with very low intensity. CV curves for the following 4 cycles exhibit repeatable redox characteristics (see Figure S9-Figure S13). The redox pair that centered at $2.5 \mathrm{~V}$ is in good agreement with previous work on $\mathrm{Li}_{3} \mathrm{PS}_{4}$ reported by M. Li [72]. The extremely low redox current under CV test indicates that samples for $\mathrm{x}=73.75$ and $\mathrm{x}=75$ (mainly $\mathrm{Li}_{3} \mathrm{PS}_{4}$ ) are electrochemical stable under oxidation condition.

To further investigate the influence of electrochemical reaction on the interface between cathode and hybrid electrolyte, the cathodes after $40^{\text {th }}$ charge are analyzed by SEM and XPS. For the batteries with $\mathrm{x}=70,71.25$ and $\mathrm{x}=72.5$, a gel-like thick layer is observed on the cathode that covers the porous structure of S-C composite (Figure 6b-d), while this layer is absent for the batteries with $\mathrm{x}=73.75$ and $\mathrm{x}=75$ (Figure 6e-f) and the porous morphology of the pristine S-C cathode (Figure S14) is almost unchanged. This is in good accordance with the CV results of the asymmetric half cells, where the redox current of the lithium phosphate samples is much higher at $\mathrm{x}=70,71.25$ and $\mathrm{x}=72.5$ than that at $\mathrm{x}=73.75$ and $\mathrm{x}=75$ under the operating voltage of the Li-S battery cathode. The XPS spectra collected from the cathode surface after 40 cycles are recorded in Figure 6 (g-h) and Figure S15. In addition to the peaks attributed to Li salts and their decomposition products $\left(\mathrm{SO}_{2} \mathrm{CF}_{3}, \mathrm{~S} 2 \mathrm{p} 3 / 2,169.6 \mathrm{~cm}^{-1}\right.$; $\mathrm{SO}_{2} \mathrm{CF}_{2} / \mathrm{LiS}_{\mathrm{x}} \mathrm{O}_{\mathrm{y}}, \mathrm{S} 2 \mathrm{p} 3 / 2,167.4 \mathrm{~cm}^{-1}$ ) [64], S 2p3/2 peak positioned at $164.1 \mathrm{~cm}^{-1}$ and P 2 p3/2 peak centered at $134.3 \mathrm{~cm}^{-1}$ can be detected for SSEs with low $\mathrm{Li}_{2} \mathrm{~S}$ content, which can be assigned to $\mathrm{P}-\mathrm{S} / \mathrm{S}-\mathrm{S}$ due to parasitic reaction between lithium 
thiophosphates and ether-based solvent $[45,61,63]$. This peak is absent for SSEs with high $\mathrm{Li}_{2} \mathrm{~S}$ content $(\mathrm{x}=73.75$ and $\mathrm{x}=75)$, which corresponds to the absence of gel-like layer in these samples. Feeble S 2p3/2 peak at $161.6 \mathrm{~cm}^{-1}$ and $\mathrm{P} 2 \mathrm{p} 3 / 2$ peak at 132.3 $\mathrm{cm}^{-1}$, which jointly belong to $\mathrm{PS}_{4}{ }^{3-}[45,61,62]$, can also be observed. This could be originated from a trace of residual of lithium thiophosphates during the cell disassembling process $(\mathrm{x}=73.75$ and $\mathrm{x}=75)$.

Therefore, it is proposed that the gel-like layer is formed by the redox product of the lithium phosphate separator. As mentioned above, the lithium phosphate with low $\mathrm{Li}_{2} \mathrm{~S}$ content tends to be decomposed by ether-based solvent. The partially soluble decomposition product $\mathrm{Li}_{2} \mathrm{~S} \cdot \mathrm{P}_{2} \mathrm{~S}_{5}$ can diffuse to the active sites on the cathode, and therefore promotes the electrochemical decomposition of the lithium thiophosphates. This can be further confirmed by carefully reexamining the galvanostatic charge-discharge profiles of the batteries with $x=70,71.25$ (Figure 2b), where an additional discharge plateau is observed at the beginning of discharge stage and an additional charge plateau at the end of charge stage and consequently exceeding theoretical specific capacity. The gel-like layer can impede $\mathrm{Li}^{+}$diffuse to the active site of S therefore deteriorates electrochemical reaction, resulting in the poor cycling stability at $\mathrm{x}=70,71.25$ and $\mathrm{x}=72.5$. This gel-like layer is absent at $\mathrm{x}=73.75$ and $\mathrm{x}=75$ due to the high stability of these two solid-state separators with the cathode, and consequently good battery cycling stability is achieved. 

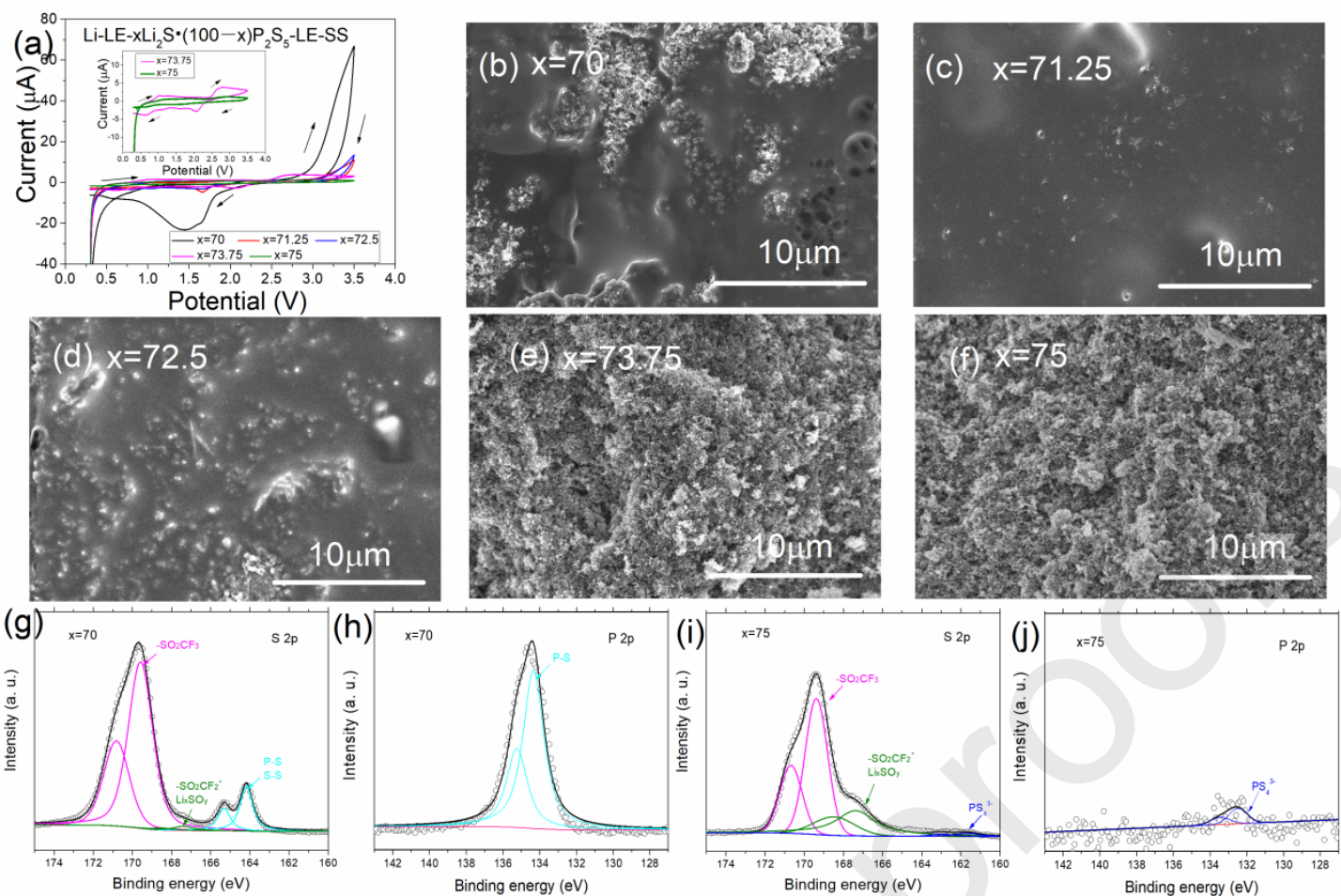

Figure 6. Stability of the sulfide solid electrolyte (SSEs)/liquid electrolyte (LE) interface with the

cathode. (a) Cyclic voltammetry of an asymmetric cell structure of - )Li/SSEs /LE/SS(+ with scanning rate $0.1 \mathrm{mV} / \mathrm{s}$. (b-f) SEM images showing morphology changes of the cathode surface after battery test. (g-j) XPS analysis for the above cathode surface of $b(x=70)$ and $f(x=75)$

The electrochemical stability analysis of the lithium thiophosphate reveals that low $\mathrm{Li}_{2} \mathrm{~S}$ content favors the formation of $\mathrm{Li}_{3} \mathrm{PS}_{4} \mathrm{SEI}$ layer on $\mathrm{Li}$, resulting in good stability with the anode, while high $\mathrm{Li}_{2} \mathrm{~S}$ content exhibit excellent stability with the cathode. Consequently, the most stable discharge plateau is achieved at $\mathrm{x}=73.75$, as shown in Figure 2d. However, the formation of $\mathrm{Li}_{3} \mathrm{PS}_{4} \mathrm{SEI}$ layer increases the interfacial resistance and therefore enlarges the overpotential of the battery. This is also in good accordance with the higher second discharge voltage plateau and lower over-potential for SSEs $\mathrm{x}=75$ than for $\mathrm{x}=73.75$ in Figure 2b,c. Despite the slightly lower cycling stability of the battery with $x=75$, it compromises of good chemical/electrochemical stability, low overpotential, high capacity and good maintenance of both the cathode and Li anode structure.

Finally, a hybrid Li-S battery with SSEs $\mathrm{x}=75$, which exhibits comprehensive 
performance advantages, is chosen for a long-term galvanostatic charge-discharge test at $0.2 \mathrm{C}$. The battery performance is recorded in Figure 7. The hybrid Li-S battery successfully runs more than 400 cycles with an initial discharge capacity of 1310.4 $\mathrm{mAh} / \mathrm{g}$ and charge capacity of $1373.3 \mathrm{mAh} / \mathrm{g}$, which decreases to $551.0 \mathrm{mAh} / \mathrm{g}$ and $548.7 \mathrm{mAh} / \mathrm{g}$, respectively. The capacity retention stays about $42.05 \%$ after 400 cycles with an average capacity fading rate of $0.14 \%$ /cycle. The Li-S battery with LE shows similar initial discharge capacity of $1231.4 \mathrm{mAh} / \mathrm{g}$ and charge capacity of 1344.1 $\mathrm{mAh} / \mathrm{g}$, however it ends up with $329.3 \mathrm{mAh} / \mathrm{g}$ and $357.6 \mathrm{mAh} / \mathrm{g}$ after 400 cycles. In addition, the hybrid Li-S battery displays a coulombic efficiency close to $100 \%$ during battery operation, far exceeds that of the Li-S battery with LE. Therefore, the hybrid electrolyte with SSEs $\mathrm{x}=75$ successfully solves the polysulfides shuttle problem and yields a long cycling life due to the excellent interfacial stability of the lithium thiophosphate separator with the anode and the cathode. 


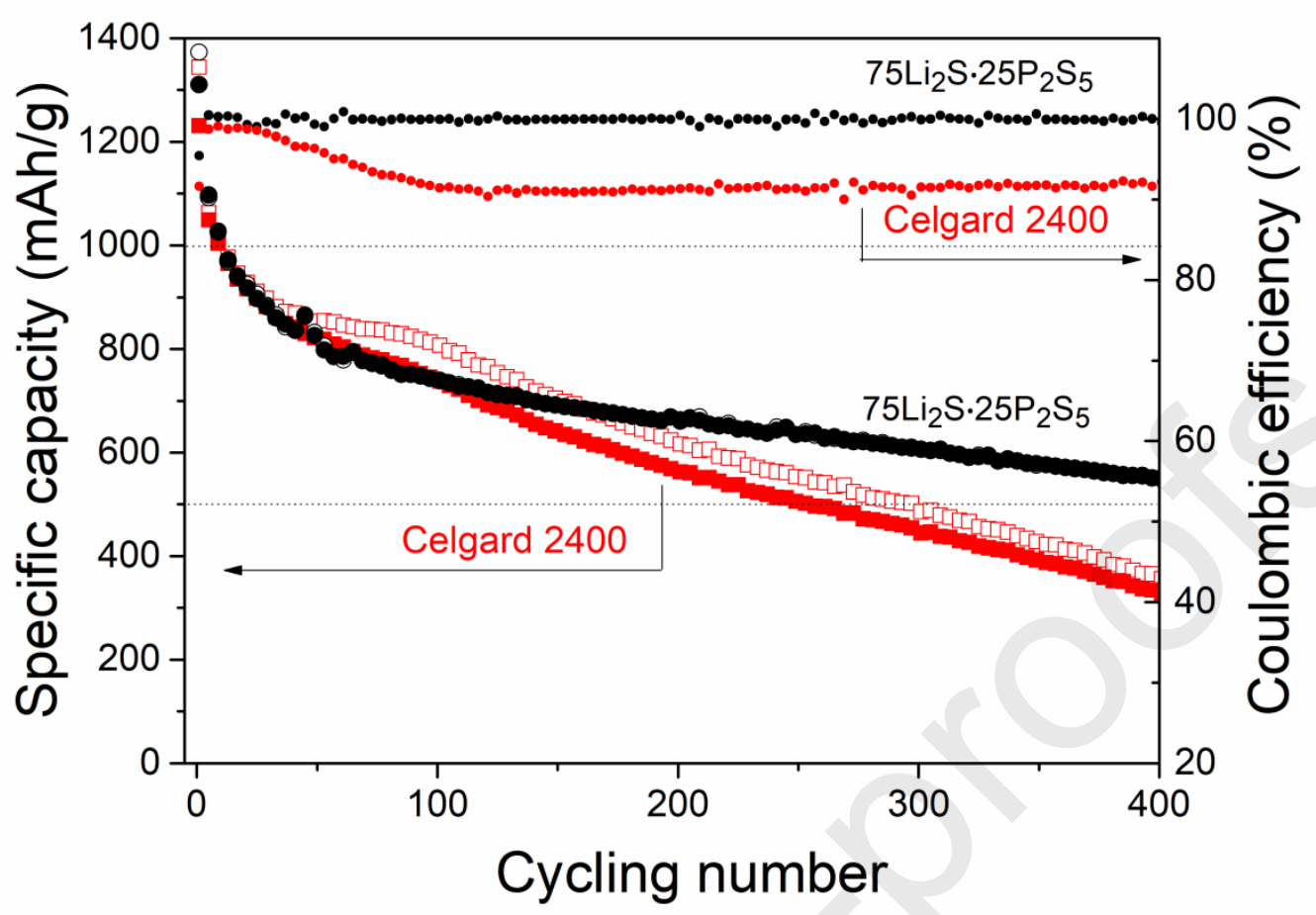

Figure 7. Cycling performance and coulombic efficiency of a conventional organic electrolyte and hybrid Li-S batteries with lithium thiophosphate of $\mathrm{x}=75$. The rate is $0.2 \mathrm{C}$.

\section{Conclusions}

Lithium thiophosphates $\mathrm{xLi}_{2} \mathrm{~S} \cdot(100-\mathrm{x}) \mathrm{P}_{2} \mathrm{~S}_{5}(70 \leq \mathrm{x} \leq 75$, SSEs $)$ were synthesized using high energy ball milling plus low temperature annealing, and were used as solid electrolyte separator to fabricate hybrid Li-S batteries. As $\mathrm{Li}_{2} \mathrm{~S}$ content increases from $x=70$ to $x=75$, the major phase gradually transforms from $\mathrm{Li}_{7} \mathrm{P}_{3} \mathrm{~S}_{11}$ to $\mathrm{Li}_{3} \mathrm{PS}_{4}$ with both two phase existing at $x=71.25$. This phase change influences the electrochemical stability of lithium thiophosphate with the electrodes. $\mathrm{Li}_{7} \mathrm{P}_{3} \mathrm{~S}_{11}$ favors the formation of a SEI layer containing $\mathrm{Li}_{3} \mathrm{PS}_{4}$ and therefore improves the interfacial stability with $\mathrm{Li}$ anode, while $\mathrm{Li}_{3} \mathrm{PS}_{4}$ exhibits low redox current under the operating voltage of the cathode so it behaves more stable than $\mathrm{Li}_{7} \mathrm{P}_{3} \mathrm{~S}_{11}$ with the cathode. The stability with 
cathode is more important for the battery performance. Consequently, the hybrid Li-S batteries at $\mathrm{x}=73.75$ and 75 mainly composed of $\mathrm{Li}_{3} \mathrm{PS}_{4}$ exhibit better cycling performance than those at $\mathrm{x}=70$ and 71.25 . High battery performance of more than 400 cycles at $0.2 \mathrm{C}$ is realized at $\mathrm{x}=75$ due to its excellent compatibility with both the anode and the cathode.

\section{CRediT authorship contribution statement}

Yang-Hai Xu: Conceptualization, Methodology, Visualization, Software, Writing - original draft, Writing - review \& editing. Wen-Zhi Li: Validation, Investigation and Data curation. Bo Fan: Resources, Investigation, Methodology, Writing - review \& editing. Ping Fan: Investigation, Validation, Supervision. Zhong-Kuan Luo: Investigation, Validation, Methodology. Fang Wang: Methodology, Writing - review \& editing. Xiang-Hua Zhang: Investigation, Validation, Writing review \& editing. Hong-Li Ma: Formal analysis, Writing - review \& editing. Bai Xue: Resources, Supervision, Writing - review \& editing.

\section{Declaration of competing interest}

The authors declare no competing financial interests.

\section{Acknowledments}

The work is financially supported by the National Science Foundation of China (NFSC) project (No. 51702216), the Natural Science Foundation of Guangdong 
Province (No. 2020A1515011430), Shenzhen Science and Technology Foundation (JCYJ20180507182106754), State Key Laboratory of Silicon Materials Visiting

Scholar Fund (SKL2020-10) and support from Postdoctoral Science Foundation of China.

Appendix A. Supplementary data

Supplementary data to this article can be found online at https://doi.org/10.1016/j.apsusc. x0xx00000x.

\section{References}


(a)

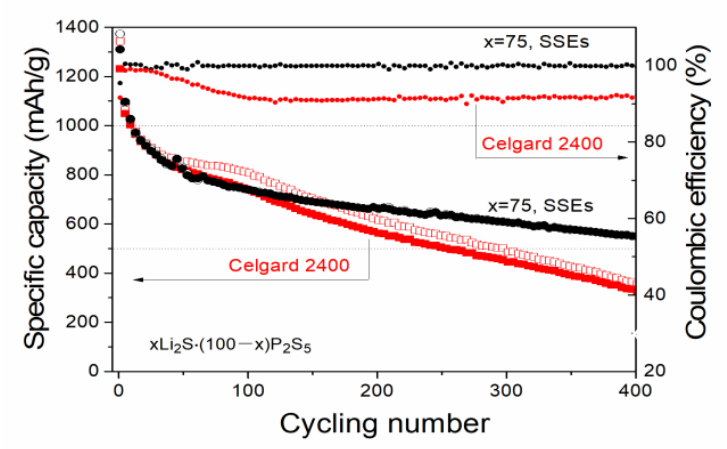

(b)

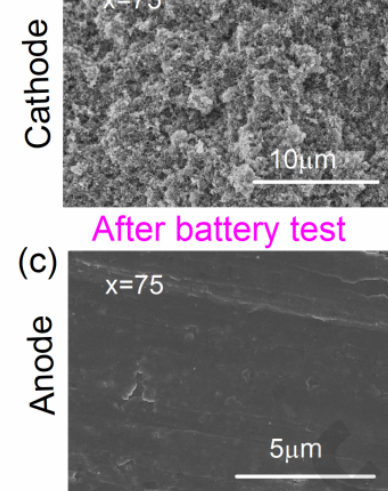

Hybrid Li-S battery $(x=75)$ yields 400 cycles due to its excellent compatibility with the electrodes. 
[1] A. Manthiram, Y. Fu, S. H. Chung, C. Zu and Y. S. Su, Rechargeable Lithium-Sulfur Batteries, Chem. Rev. 114 (2014) 11751-11787.

[2] X. L. Ji, K. T. Lee and L. F. Nazar, A highly ordered nanostructured carbon-sulphur cathode for lithium-sulphur batteries, Nat. Mater. 8 (2009) 500-506.

[3] P.G. Bruce, S.A. Freunberger, L.J. Hardwick, J.-M. Tarascon, $\mathrm{Li}_{-} \mathrm{O}_{2}$ and $\mathrm{Li}-\mathrm{S}$ batteries with high energy storage Nat. Mater. 12(2012) 19-29.

[4] S.-E. Cheon, K.-S. Ko, J.-H. Cho, S.-W. Kim, E.-Y. Chin, and H.-T. Kim, Rechargeable Lithium Sulfur Battery, J. Electrochem. Soc. 150 (2003) A800-A805.

[5] X. Ji and L. F. Nazar, Advances in Li-S batteries, J. Mater. Chem., 20(2010) 9821-9826.

[6] A. Hayashi, A. Sakuda and M. Tatsumisago, Development of Sulfide Solid electrolytes and interface Formation Processes for Bulk-Type All-Solid- State Li and Na Batteries, Front. Energy Res. 4(2016), 25.

[7] X. Fan, W. Sun, F. Meng, A. Xing, J. Liu, Advanced chemical strategies for lithium-sulfur batteries: A review, Green Energy \& Environment 3 (2018) 2-19.

[8] G. Zheng, Q. Zhang, J. J. Cha, Y. Yang, W. Li, Z. W. Seh, and Y. Cui, Amphiphilic surface modification of hollow carbon nanofibers for improved cycle life of lithium sulfur batteries, Nano Lett. 13(2013) 1265-1270.

[9] Zhang, B., Qin, X., Li, G. R., Gao, X. P., Enhancement of long stability of sulfur cathode by encapsulating sulfur into micropores of carbon spheres, Energy Environ. Sci. 3(2010) 1531.

[10] J. Shim, K. A. Striebel and E. J. Cairns, The Lithium/Sulfur Rechargeable Cell: Effects of Electrode Composition and Solvent on Cell Performance, J. Electrochem. Soc. 149(2002) A1321- 
A1325.

[11] Sheng S. Zhang, Role of $\mathrm{LiNO}_{3}$ in rechargeable lithium/sulfur battery, Electrochimica Acta 70 (2012) 344-348.

[12] B. D. Adams , E. V. Carino, J. G. Connell, K. S. Han, R. Cao, J. Chen, J. Zheng, Q. Li , K. T. Mueller, W. A. Henderson, J.-G. Zhang, Long term stability of Li-S batteries using high concentration lithium nitrate electrolytes, Nano Energy 40(2017) 607-617.

[13] Y.-J. Choi, Y.-D. Chung, C.-Y. Baek, K.-W. Kim, H.-J. Ahn and J.-H. Ahn, Effects of carbon coating on the electrochemical properties of sulfur cathode for lithium/sulfur cell, J. Power Sources 2008, 184, 548-552.

[14] L. Fan, M. Li, X. Li, W. Xiao, Z. Chen, and Jun Lu, Interlayer Material Selection for Lithium-Sulfur Batteries, Joule 3(2019), 361-386.

[15] L. Yuan, X. Qiu, L. Chen, W. Zhu, New insight into the discharge process of sulfur cathode by electrochemical impedance spectroscopy, J. Power Sources 189 (2009) 127-132.

[16] Y. Yang, G. Zheng and Y. Cui, A separator-free lithium/polysulfide semi-liquid battery for large-scale energy storage, Energy Environ. Sci. 6(2013) 1552-1558.

[17] Z. Lin and C. Liang, Lithium-sulfur batteries: from liquid to solid cells, J. Mater. Chem. A 3(2015) 936-958.

[18] A. Hayashi, T. Ohtomo, F. Mizuno, K. Tadanaga, M. Tatsumisago, All-solid-state Li/S batteries with highly conductive glass-ceramic electrolytes, Electrochem. Commun., 5(2003) $701-705$.

[19] M. Agostini , Y. Aihara, T. Yamada , B. Scrosati, J. Hassoun, A lithium-sulfur battery using a solid, glass-type $\mathrm{P}_{2} \mathrm{~S}_{5}-\mathrm{Li}_{2} \mathrm{~S}$ electrolyte, Solid State Ionics, 244(2013) 48-51.

[20] S. Huang, R. Guan, S. Wang, M. Xiao, D. Han, L. Sun, Y. Meng, Polymers for High Performance Li-S Batteries: Material Selection and Structure Design, Progress in Polymer Science 89(2019),19-60.

[21] R.C. Xu, X.H. Xia, S.Z. Zhang, D. Xie, X.L. Wang, J.P. Tu, Interfacial challenges and progress for inorganic all-solid-state lithium batteries, Electrochim. Acta 284(2018) 177-187.

[22] C. Sun , J. Liu , Y. Gong, D. P. Wilkinson, J. Zhang, Recent advances in all-solid-state 
rechargeable lithium batteries, Nano Energy 33(2017) 363-386.

[23] Q.Wang, J. Jin, X. Wu, G. Ma, J. Yang and Z. Wen, A shuttle effect free lithium sulfur battery based on a hybrid electrolyte, Phys. Chem. Chem. Phys., 16(2014) 21225-21229.

[24] M. Keller, A. Varzi, S. Passerini, Hybrid electrolytes for lithium metal batteries, J. Power Sources 392(2018) 206-225.

[25] Y. Lu, K. Korf, Y. Kambe, Z. Tu, and L. A. Archer, Ionic-liquid-nanoparticle hybrid electrolytes: applications in lithium metal batteries, Angew. Chem. Int. Ed. 53(2014) 488-492.

[26] O.Sheng, C. Jin, J. Luo, H. Yuan, C. Fang, H. Huang, Y. Gan, J. Zhang, Y. Xia, C. Liang, W.Zhang and X. Tao, Ionic conductivity promotion of polymer electrolyte with ionic liquid grafted oxides for all-solid-state lithium-sulfur batteries, J. Mater. Chem. A 5(2017) 1293412942.

[27] Q. Wang, Z. Wen, J. Jin, J. Guo, X. Huang, J. Yang and C. Chen, A gel-ceramic multi-layer electrolyte for long-life lithium sulfur batteries, Chem. Commun. 52(2016) 1637-1640.

[28] X. Yu, Z. Bi, F. Zhao, and A. Manthiram, Hybrid Lithium-Sulfur Batteries with a Solid Electrolyte Separator and Lithium Polysulfide Catholyte, ACS Appl. Mater. Interfaces, 7(2015) $16625-16631$.

[29] X. Judez, H. Zhang, C. Li, G. G. Eshetu, Y. Zhang, J. A. González-Marcos, M. Armand, and L. M. Rodriguez-Martinez, Polymer-Rich Composite Electrolytes for All-Solid-State Li-S Cells, J. Phys. Chem. Lett. 8(2017) 3473-3477.

[30] X. Yu and A. Manthiram, Electrode-Electrolyte Interfaces in Lithium-Sulfur Batteries with Liquid or Inorganic Solid Electrolytes, Acc. Chem. Res. 50(2017) 2653-2660.

[31] S. Gu, X. Huang, Q. Wang, J. Jin, Q. Wang, Z. Wen and R. Qian, A hybrid electrolyte for long-life semi-solid-state lithium sulfur batteries, J. Mater. Chem. A 5(2017) 13971-13975.

[32] S. Wang, Y. Ding, G. Zhou, G. Yu, and A. Manthiram, Durability of the $\mathrm{Li}_{1+\mathrm{x}} \mathrm{Ti}_{2-\mathrm{x}} \mathrm{Al}_{\mathrm{x}}\left(\mathrm{PO}_{4}\right)_{3}$ solid electrolyte in lithium-sulfur batteries, ACS Energy Lett. 1(2016) 1080-1085.

[33] N. Kamaya, K. Homma, Y. Yamakawa,M. Hirayama, R. Kanno, M. Yonemura, T.Kamiyama, Y. Kato, S. Hama, K. Kawamoto and A. Mitsui, A lithium superionic conductor, Nat. Mater. 10(2011) 682-686. 
[34] Y. Seino, T. Ota, K. Takada, A. Hayashi and M. Tatsumisago, A sulphide lithium super ion conductor is superior to liquid ion conductors for use in rechargeable batteries, Energy Environ. Sci. 7(2014) 627-631.

[35] P. Bron, S. Johansson, K. Zick, J. S.Günne, S. Dehnen, B. Roling, $\mathrm{Li}_{10} \mathrm{SnP}_{2} \mathrm{~S}_{12}$ : An Affordable Lithium Superionic Conductor, J. Am. Chem. Soc. 135(2013) 15694-15697.

[36] Y. Kato, S. Hori, T. Saito, K. Suzuki, M. Hirayama, A. Mitsui, M. Yonemura, H. Iba and R. Kanno, High-power all-solid-state batteries using sulfide superionic conductors, Nat. Energy. 1(2016) 16030.

[37] S. Wang, Y. Zhang, X. Zhang, T. Liu, Y.-H. Lin, Y. Shen, L. Li, and C.-W. Nan, High-Conductivity Argyrodite $\mathrm{Li}_{6} \mathrm{PS}_{5} \mathrm{Cl}$ Solid Electrolytes Prepared via Optimized Sintering Processes for All-Solid-State Lithium-Sulfur Batteries, ACS Appl. Mater. Interfaces 10(2018) 49 42279-42285.

[38] S. Wenzel, D.A. Weber, T. Leichtweiss, M.R. Busche, J. Sann, J. Janek, Interphase formation and degradation of charge transfer kinetics between a lithium metal anode and highly crystalline $\mathrm{Li}_{7} \mathrm{P}_{3} \mathrm{~S}_{11}$ solid electrolyte, Solid State Ion, 286 (2016) 24-33.

[39] S. P. Ong, Y. Mo, W. D. Richards, L. Miara, H. S. Lee, G. Ceder, Phase Stability, Electrochemical Stability and Ionic Conductivity of The $\mathrm{Li}_{10 \pm 1} \mathrm{MP}_{2} \mathrm{X}_{12}(\mathrm{M}=\mathrm{Ge}, \mathrm{Si}, \mathrm{Sn}, \mathrm{Al}$ or $\mathrm{P}$, and $\mathrm{X}=\mathrm{O}, \mathrm{S}$ or Se) Family of Superionic Conductors. Energy Environ. Sci. 6(2013) 148-156.

[40] S. Wenzel, S. Randau, T. Leichtweiß, D.A. Weber, J. Sann, W.G. Zeier, J. Janek, Direct Observation of the Interfacial Instability of the Fast Ionic Conductor $\mathrm{Li}_{10} \mathrm{GeP}_{2} \mathrm{~S}_{12}$ at the Lithium Metal Anode, Chem. Mater. 28 (2016) 2400-2407.

[41] R. Xu, F. Han, X. Ji, X. Fan, J. Tu, C. Wang, Interface engineering of sulfide electrolytes for all-solid-state lithium batteries, Nano Energy 53 (2018) 958-966.

[42] Y. Lu, Z. Tu and L. A. Archer, Stable lithium electrodeposition in liquid and nanoporous solid electrolytes. Nat. Mater. 13(2014) 961.

[43] Y. Yuan, F. Wu, Y.g Bai, Y. Li, G. Chen , Z. Wang, C. Wu. Regulating Li deposition by constructing LiF-rich host for dendrite-free lithium metal anode. Energy Storage Mater. 16(2019) 
$411-418$.

[44] B. Zheng, J. Zhu, H. Wang, M. Feng, E. Umeshbabu, Y. Li, Q.-H. Wu, and Y. Yang, Stabilizing $\mathrm{Li}_{10} \mathrm{SnP}_{2} \mathrm{~S}_{12} / \mathrm{Li}$ Interface via an in Situ Formed Solid Electrolyte Interphase Layer, ACS Appl. Mater. Interfaces, 10(2018) 25473-25482.

[45] J. Liang, X. Li, Y. Zhao, L. V. Goncharova, G. Wang, K. R. Adair, C. Wang, R. Li, Y. Zhu, Y. Qian, L. Zhang, R. Yang, S. Lu and X. Sun, In Situ $\mathrm{Li}_{3} \mathrm{PS}_{4}$ Solid-State Electrolyte Protection Layers for Superior Long-Life and High-Rate Lithium-Metal Anodes, Adv. Mater. 30(2018) 1804684.

[46] Y.-H. Xu, Q.-F. Zhang, Bo. Fan, B. Xue, H.-J. Chen, X.-H. Zhang, Z.-K. Luo, F. Wang, D. Le Coq, L. Calvez, H.-L. Ma and P. Fan, An extremely high rate Li-S battery with hybrid electrolyte, J. ALLOY COMPD. 845 (2020) 156261.

[47] F. Han, A.S. Westover, J. Yue, X. Fan, F. Wang, M. Chi, D.N. Leonard, N.J. Dudney, H. Wang, C. Wang, High electronic conductivity as the origin of lithium dendrite formation within solid electrolytes, Nat. Energy 4 (2019) 187-196.

[48] F. Mizuno, A. Hayashi, K. Tadanaga, M. Tatsumisago, High lithium ion conducting glass-ceramics in the system $\mathrm{Li}_{2} \mathrm{~S}-\mathrm{P}_{2} \mathrm{~S}_{5}$, Solid State Ionics, 177 (2006) 2721-2725.

[49] J. Wei, H. Kim, D.-C. Lee, R. Hu, F. Wu, H. Zhao, F. M. Alamgir, G. Yushin, Influence of annealing on ionic transfer and storage stability of $\mathrm{Li}_{2} \mathrm{~S}-\mathrm{P}_{2} \mathrm{~S}_{5}$ solid electrolyte, J. Power Sources 294 (2015) 494-500.

[50] M. Calpa, N. C. Rosero-Navarro, A. Miura and K. Tadanaga, Instantaneous preparation of high lithium-ion conducting sulfide solid electrolyte $\mathrm{Li}_{7} \mathrm{P}_{3} \mathrm{~S}_{11}$ by a liquid phase process, RSC Adv. 7(2017) 4649.

[51] Ö. Kudu, T. Famprikis, B. Fleutot, M.-D. Braida, T. Le Mercier, M. S. Islam, C. Masquelier, A review of structural properties and synthesis methods of solid electrolyte materials in the $\mathrm{Li}_{2} \mathrm{~S}-$ $\mathrm{P}_{2} \mathrm{~S}_{5}$ binary system, J. Power Sources 407 (2018) 31-43.

[52] Y. Zhang, K. Chen, Y. Shen, Y. Lin, C.-W. Nan, Synergistic effect of processing and composition $\mathrm{x}$ on conductivity of $\mathrm{xLi} \mathrm{i}_{2} \mathrm{~S}-(100-\mathrm{x}) \mathrm{P}_{2} \mathrm{~S}_{5}$ electrolytes, Solid State Ionics 305 (2017) 16. 
[53] B. Fan, Q. Zhang, Z. Luo, X. Zhang, H.Ma, P. Fan, B. Xue, Influence of precipitate/supernatant ratio during liquid-phase synthesis of solid electrolyte $\mathrm{Li}_{7} \mathrm{P}_{3} \mathrm{~S}_{11}$, Solid State Ionics 343 (2019) 115073.

[54] S. Ito, M. Nakakita, Y. Aihara, T. Uehara, N. A Machida, Synthesis of Crystalline $\operatorname{Li}_{7} \mathrm{P}_{3} \mathrm{~S}_{11}$ Solid Electrolyte from 1,2-Dimethoxyethane Solvent. J. Power Sources, 271 (2014), 342-345.

[55] B. Xue, B. Fan, B. Li, L. Chen, F. Wang, Z. Luo, X. Zhang, H. Ma, Solvent-Assisted Ball Milling for Synthesizing Solid Electrolyte $\mathrm{Li}_{7} \mathrm{P}_{3} \mathrm{~S}_{11}$, J. Am. Ceram. Soc. (102)2019, 3402-3410.

[56] Y. Wang, D. Lu, M. Bowden, P. Z. El Khoury, K. S. Han, Z. D. Deng, J. Xiao, J.-G. Zhang, J. Liu, Mechanism of Formation of $\mathrm{Li}_{7} \mathrm{P}_{3} \mathrm{~S}_{11}$ Solid Electrolytes through Liquid Phase Synthesis, Chem. Mater. (30)2018, 990-997.

[57] B. Fan, Y. Xu, R. Ma, Z. Luo, F. Wang, X. Zhang, H. Ma, P. Fan, B. Xue, and W. Han, Will Sulfide Electrolytes be Suitable Candidates for Constructing a Stable Solid/Liquid Electrolyte Interface? ACS Appl. Mater. Interfaces, (12)2020, 52845-52856.

[58] Y. Shao, H. Wang, Z. Gong, D. Wang, B. Zheng, J. Zhu, Y. Lu, Y.-S. Hu, X. Guo, H. Li, X. Huang, Y. Yang, C.-W. Nan and L. Chen, Drawing a Soft Interface: An Effective Interfacial Modification Strategy for Garnet-Type Solid-State Li Batteries, ACS Energy Lett. 3(2018) $1212-1218$.

[59] M. Nagao, A. Hayashi, M. Tatsumisago, T. Kanetsuku, T. Tsuda, S. Kuwabata, In situ SEM study of a lithium deposition and dissolution mechanism in a bulk-type solid-state cell with a $\mathrm{Li}_{2} \mathrm{~S}-\mathrm{P}_{2} \mathrm{~S}_{5}$ solid electrolyte, Phys. Chem. Chem. Phys. 15 (2013) 18600-18606.

[60] L. Porz, T. Swamy, B.W. Sheldon, D. Rettenwander, T. Frömling, H.L. Thaman, S. Berendts, R. Uecker, W.C. Carter, Y.M. Chiang, Mechanism of Lithium Metal Penetration through Inorganic Solid Electrolytes, Adv. Energy Mater. 7 (2017), 1701003.

[61] C. Dietrich, R. Koerver, M. W. Gaultois, G. Kieslich, G. Cibin, J. Janek and W. G. Zeier., Spectroscopic characterization of lithium thiophosphates by XPS and XAS - a model to help monitor interfacial reactions in all-solid-state batteries. Phys. Chem. Chem. Phys. 20(2018), 20088-20095.

[62] C. $\mathrm{Zu}, \mathrm{M}$. Klein, A. Manthiram, Activated $\mathrm{Li}_{2} \mathrm{~S}$ as a High-Performance Cathode for 
Rechargeable Lithium-Sulfur Batteries, J. Phys. Chem. Lett. 5( 2014) 3986.

[63] N. Tanibata, H. Tsukasaki, M. Deguchi, S. Mori, A. Hayashi and M. Tatsumisago, A novel discharge-charge mechanism of a $\mathrm{S}-\mathrm{P}_{2} \mathrm{~S}_{5}$ composite electrode without electrolytes in all solid-state Li/S batteries, J. Mater. Chem. A 5(2017) 11224-11228.

[64] M. R. Busche, T. Drossel, T. Leichtweiss, D. A. Weber, M. Falk, M. Schneider, M.-L. Reich, H. Sommer, P. Adelhelm and J. Janek. Dynamic formation of a solid-liquid electrolyte interphase and its consequences for hybrid-battery concepts. Nat. Chem. 8(2016) 426-434.

[65] D. Aurbach, E. Pollak, R. Elazari, G. Salitra, C. S. Kelley, J. Affinito, On the Surface Chemical Aspects of Very High Energy Density Rechargeable Li-Sulfur Batteries, J. Electrochem. Soc. 156(2009) A694-A702.

[66] X. Fan, X. Ji, F. Han, J. Yue, J. Chen, L. Chen, T. Deng, J. Jiang, C. Wang, Fluorinated solid electrolyte interphase enables highly reversible solid-state Li metal battery, Sci. Adv. 4(2018), eaau9245.

[67] J. Kim, T. Kim, Y. Jeong, K. Lee, K. Park, S. Yang, C. Park, Lithium-Sulfur Batteries: Stabilization of Insoluble Discharge Products by Facile Aniline Modification for High Performance Li-S Batteries, Adv. Energy Mater. 5(2015) 1500268.

[68] Y. Chu, Z. Fu, Q. Qin, Cobalt ferrite thin films as anode material for lithium ion batteries, Electrochim. Acta 49(2004) 4915-4921.

[69] Z. Lin, Z. Liu, W. Fu, N. J. Dudney, C. Liang, Phosphorous Pentasulfide as a Novel Additive for High-Performance Lithium-Sulfur Batteries. Adv. Funct. Mater. 23(2013), 1064-1069.

[70] Y. Lu, S.Gu, X. Hong, K. Rui, X. Huang, J. Jin, C. Chen, J. Yang, Z. Wen, Pre-modified $\mathrm{Li}_{3} \mathrm{PS}_{4}$ based interphase for lithium anode towards high performance Li-S battery, Energy Storage Mater. 11 (2018) 16-23.

[71] Zhu, Y., He, X. \& Mo, Y. Origin of Outstanding Stability in the Lithium Solid Electrolyte Materials: Insights from Thermodynamic Analyses Based on First-Principles Calculations, ACS Appl. Mater. Interfaces, 7 (2015) 23685-23693.

[72] M. Li, Z. Bai, Y. Li, L. Ma, A. Dai, X. Wang, D. Luo, T. Wu, P. Liu, L. Yang, K. Amine, Z. Chen and J. Lu, Electrochemically primed functional redox mediator generator from the 
decomposition of solid state electrolyte,. Nat. Commun. 10 (2019) 1890. 


\section{Declaration of interests}

The authors declare that they have no known competing financial interests or personal relationships that could have appeared to influence the work reported in this paper.

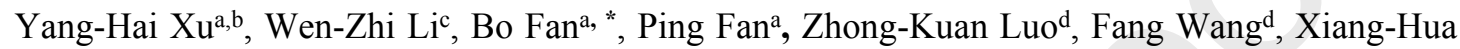
Zhang ${ }^{\mathrm{a}, \mathrm{e}}$, Hong-Li Ma ${ }^{\mathrm{e}}$, Bai Xue ,** $^{*}$

a Shenzhen Key Laboratory of Advanced Thin Films and Applications, Institute of Thin Film Physics and Applications, College of Physics and Energy, Shenzhen University, 518060 Shenzhen, China.

b Key Laboratory of Optoelectronic Devices and Systems of Ministry of Education and Guangdong Province, College of Optoelectronic Engineering, Shenzhen University, Shenzhen 518060, China.

c College of Materials Science and Engineering, Shenzhen University, 3688 Nanhai Avenue, Nanshan District, Shenzhen, 518060, China.

${ }^{\mathrm{d}}$ College of Chemistry and Environmental Engineering, Shenzhen University, 3688 Nanhai Avenue, Nanshan District, Shenzhen, 518060, China.

${ }^{\mathrm{e}}$ Laboratory of Glasses and Ceramics, Institute of Chemical Science, University of Rennes 1, Rennes, France.

f State Key Lab of Silicon Materials, Zhejiang University, Hangzhou, 310027, China.

*Corresponding author: fanb07@hotmail.com; baixue@szu.edu.cn. 